\title{
COMPETITIVE PRICING STRATEGIES OF MULTI CHANNEL SUPPLY CHAIN UNDER DIRECT SERVICING BY THE MANUFACTURER
}

\author{
Amit Sarkar and Brojeswar PaL*
}

\begin{abstract}
Internet and its accessible devices (e.g., mobiles, computers) are the unmitigated blessings to the people. Nowadays, internet connectivity almost eliminates all kinds of blockades for the verification of authentication, comparison of prices, and services for a product. Consequently, the market has been becoming more competitive compared to decision making. In this paper, we construct a multi-channel supply chain (MCSC) frameworks with traditional channels as well as a direct channel (DC), where the manufacturer provides services to the customers for both the cases. Then the optimal decisions of the manufacturer and the retailers are examined. The optimal pricing decisions and services are discussed and also compared the profits with one another under various cases (Stackelberg settings, strategic alliance, and two types of no improved service). Then the sensitivity of the service cost coefficients and the cross-channel price coefficients on the profits for each player and the supply chain is analyzed. We find out the best profitable strategies under the parameters such as service costs and the positive effects of the service on the demand rate. We also mark out the optimum level of the services so that the profit will be maximized for each player. Finally, we define an interval such that if the service costs belong to that interval, then the selling price of the DC would be lesser than the wholesale price. These findings help companies such as automobiles, electronic goods, etc. to implement the best strategies to increase their profit.
\end{abstract}

Mathematics Subject Classification. 90B06.

Received July 12, 2019. Accepted June 13, 2020.

\section{INTRODUCTION}

In present times, commerce on the internet puts its emerging effects on the everyday life of a very vast and wide range of people. It is very much accessible to most people all over the world. As a result, the popularity of online business mediums like Amazon, eBay, Asos, etc. increases day by day [18]. Online marketing is a digitized shop, in which a customer can choose and buy products from internet websites designed by online sellers, and some mailing services send them to the buyers' doorsteps. Besides online marketing sites like Amazon, the manufacturers of many reputed companies like Hewlett-Packard, Reebok, Nike, Samsung, etc. have also opened their online shopping sites along with the retail shop [20,40]. Clearly, through this process, the manufacturer can directly sell its products to the customers without any middleman. So, online marketing is also known as the direct channel.

Keywords. Multi-channel supply chain, price, service, Stackelberg settings, strategic alliance.

Department of Mathematics, The University of Burdwan, Burdwan 713104, India.

*Corresponding author: brojo_math@yahoo.co.in 
Although the traditional retail channel also played an essential role as direct channels. The retailer can promote to increase the selling rate their products through many ways like an advertisement, attractive designs of the showrooms, the behavior of the salesmen, and also give some useful information and guidelines for using the products [47]. Besides, the customers who have the intention to inspect the product physically, do not buy through online market generally $[29,36]$.

In today's economic strategies, most of the well-known reputed companies sell their products through direct channels or retail channels but give the on-site-services to the customers directly [24]. In these cases, the manufacturers take full responsibility if products do not perform flawlessly within some predefined period mentioned by themselves. Therefore the retailers do not need to resolve any problems related to the defective products physically. Consequently, this business policy becomes more acceptable to retailers $[7,46]$.

In this paper, we firstly consider a dual-channel supply chain (DCSC) model framework with one online marketing channel and two retail channels. It is also taken into account that if the selling products through any channels need services like installation, damage repairing, or other problems related to the products, the manufacturer provides it directly to the customers. It is also under consideration that the level of providing services and the service costs are not always equal. It may vary channel to channel and manufacturer to manufacturer. Here, we analyze three strategies: (1) Stackelberg settings (SS), (2) strategic alliance (SA), and two types of (3) no improved service (NIS). Under all these cases, we discuss the optimal pricing and servicing decisions, and examine the sensitivity of the demand rates and profit parameters for the manufacturer and the retailers. With the help of these studies, some critical observations and results can be formed in this article.

The formation of this paper is given below. In Section 2, the literature review is discussed. Section 3 introduces the assumptions, model framework, useful notations, and optimal results. The sensitivity analysis is done in Section 4 and also illustrated some results and decisions. Section 5 concludes the works and focuses some light in some ways to extend the research work in this direction.

\section{Literature REVIEW}

During the last few years, many researchers around the globe have been working on a multi-channel supply chain (MCSC) where services are provided by the players of the supply chain. Some of the works of literature are reviewed in this section. Simultaneous versus sequential play is studied in an extended game by Hamilton and Slutsky [14]. Besides this, Magrath and Hardy [24] first introduced a framework on supply chain where service was offered by the manufacturer to the distributors. In this article, the possible sequence of pricing is determined by the manufacturer and the retailers. Chiang et al. [9] considered an MCSC where the manufacturer sold his product through multi-channels. In this article, the authors introduced a direct channel along with an independent retailer where they discussed the pricing decisions of the channels and analyzed the cases when the members would be more profitable. After that, Rangaswamy and Bruggen [29] provided an overview of MCSC and talked about the benefits and losses of the chains. Also, they discussed the further scope of research in this field. After introducing a direct channel along with the traditional chain, Yao and Liu [44] and Kumar and Ruan [20] obtained the pricing policies of the manufacturer and retailer, and also compared the profits under Bertrand competition and Stackelberg settings. Rosenbloom [31] discussed the collaboration among the channels in an MCSC and created a sustainable advance of the competition avoiding channel conflict. Chen et al. [8] also considered a dual-channel supply chain with competition in service where the service was described as the lead time for online channel and product availability for the retail channels. After that, Dumrongsiri et al. [12] established some useful conditions for the equilibrium in a dual-channel supply chain. Another MCSC was considered by Wolk and Ebling [38] with deterministic demand function. They investigated the various pricing decisions of the retailers. The information-sharing techniques in the MCSC had been introduced by Yan and Pei [42] between the manufacturer and the retailer. They discussed the advantages and disadvantages of shared information under the SS. Furthermore, Lu et al. [23] designed a model with two manufacturers and a regular retailer, where the demand rates related to the customers depended on the retail prices and the manufacturers' service. They derived all the pricing decisions, profits, and demand rates under different types of strategies 
and also studied the effects of the parameters. Meanwhile, Okuda et al. [26] defined "membership-type services in manufacturing" in a supply chain, and then they analyzed it with the help of game-theoretic frameworks. In the article Hoseininia et al. [15], an MCSC was investigated with a manufacturer and an arbitrary number of the retail channels. Furthermore, Zhao et al. [46] proposed a supply chain with two manufacturers and a usual retailer, and the manufacturers offered the service to the customers to survive from the market competition. In the paper, they solved the model under different decision variables considering the manufacturing and servicing costs as fuzzy variables. In the article Vries et al. [35], they found some significant results on the relationship between contractual incentives and exploratory knowledge sharing. Kolay [19] introduced a supply chain model with a manufacturer and retailer, where both of the players committed the service to the consumers. They mainly analyzed the effects of the demand-enhancing services with the product qualities, the profits of each player, and the customers' welfare in the paper. Later on, a two-layer supply chain with a manufacturer and retailer was considered by $\mathrm{Pal}$ et al. [27], where they investigated the behaviors of the supply chain under several game settings such as centralized, manufacturer Stackelberg, retailer Stackelberg, etc. After that, Silva and Nof [32] analyzed the relation between e-Work and service-oriented approach, and revealed the condition for which the manufacturer should give services. A model framework with a manufacturer and two independent retailers was studied by Dan et al. [10], where they obtained a connection between the transshipment price and order quantity. Also, they examined the sensitivity of the parameters on different pricing decisions and profits of the players. Then Xue et al. [39] introduced a cluster supply chain that can respond to the changing demands of the competitive markets. In the paper, they first developed a new current quality of services model of manufacturer service composition and then described how to improve the service. In the article Rajagopal et al. [28], the authors reviewed 126 articles, published in various reputed journals in the year 2015-2016, on the decision-making model for the supply chain. They ascertained some fundamental concepts of the researchers in this field and also studied the best strategies of the players. They also identified the relationship between the risk measures, the decision makers risk attitude, etc. Jafari et al. [17] developed a dual-channel supply chain with one manufacturer and multiple retailers, where they discussed the pricing decisions through game-theoretic approaches. After that, Benedettini et al. [1] examined the secondary data of 74 bankrupted companies and 199 non-bankrupted companies and studied the cases to obtain in the conclusion that the primary key to surviving in the market competition was not only to sell the products successfully but to focus on the manufacturer services. In a case study, Burton et al. [5] explored that, the manufacturer could face some difficulties/challenges to serve the customers against the selling products. Here, they discussed the method to overcome from the manufacturer's point of view and also the way to develop a new service process. After that, considering refurbished or recycled defective products, Bhattacharya et al. [2] obtained the optimality condition of pricing decisions of all types of products to maximize profits. Büyüközkan and Göçer [6] reviewed the papers on the digital supply chain. The authors of the article also gave light on the main limitations and expectations of the digital supply chain and introduced some road maps to the researchers to enhance their work in this field. Furthermore, Ren [30] focused on social collaboration among manufacturer servicings. They provided some significant and meaningful results, such as different types of social relationships between services and methods to calculate the effects of them. After that, another MCSC was developed by Matsui [25], where they analyzed the decisions of the wholesale and retail prices. They mainly considered the observable delay game framework to the decision problem of the pricing decisions. Liu [22] investigated that under which conditions manufacturers produce new products or refurbished the old products or both. Besides all of these, many of the research articles like, Toloo [33], Toloo and Barat [34], Zhu and Xue [48], Yang et al. [43] and Fan et al. [13] have also been worked in this direction. We summarize some of the important literatures in Table 1.

\section{Model Formulation}

\subsection{Supply chain with retail channels}

In this paper, first we discuss the DCSC model with two traditional retail channels, namely R1 and R2 (see Fig. 1). We also consider that the services will be provided to the customers by the manufacturer only. In the supply chain, 
TABLE 1. Summary table of existing literatures.

\begin{tabular}{|c|c|c|c|c|}
\hline Representing paper(s) & Structures & Attributes & Considering strategies & Channel(s) \\
\hline Chiang et al. [9] & $\begin{array}{l}1 \text { Manufacturer, } 1 \\
\text { Retailer }\end{array}$ & Pricing & $\begin{array}{l}\text { Manufacturer Stackelberg, } \\
\text { Vertically integrated }\end{array}$ & $\begin{array}{l}1 \text { Online, } \\
1 \text { Retail channel }\end{array}$ \\
\hline Chen et al. [8] & $\begin{array}{l}1 \text { Manufacturer, } 1 \\
\text { Retailer }\end{array}$ & $\begin{array}{l}\text { Pricing, Retail service, } \\
\text { Delivery lead time }\end{array}$ & $\begin{array}{l}\text { Vertical Nash, Manufacturer } \\
\text { Stackelberg }\end{array}$ & $\begin{array}{l}1 \text { Online, } \\
1 \text { Retail channel }\end{array}$ \\
\hline Lu et al. [23] & $\begin{array}{l}2 \text { Manufacturer, } 1 \\
\text { Retailer }\end{array}$ & $\begin{array}{l}\text { Pricing, Manufacturer } \\
\text { service }\end{array}$ & $\begin{array}{l}\text { Manufacturer Stackelberg, } \\
\text { Retailer Stackelberg, Vertical } \\
\text { Nash }\end{array}$ & 2 Retail channel \\
\hline Yan and Pei [42] & $\begin{array}{l}1 \text { Manufacturer, } 1 \\
\text { Retailer }\end{array}$ & $\begin{array}{l}\text { Information sharing, } \\
\text { Pricing }\end{array}$ & Manufacturer Stackelberg & $\begin{array}{l}1 \text { Online, } \\
1 \text { Retail channel }\end{array}$ \\
\hline Okuda et al. [26] & $\begin{array}{l}1 \text { Manufacturer, } 1 \\
\text { Retailer }\end{array}$ & $\begin{array}{l}\text { Pricing, Membership- } \\
\text { type service }\end{array}$ & Vertical Nash & 1 Retail channel \\
\hline Kolay [19] & $\begin{array}{l}1 \text { Manufacturer, } 1 \\
\text { Retailer }\end{array}$ & $\begin{array}{l}\text { Demand-enhancing } \\
\text { service, Product quality, } \\
\text { Pricing }\end{array}$ & Manufacturer Stackelberg & 1 Retail channel \\
\hline Wang [37] & $\begin{array}{l}2 \text { Manufacturer, } 1 \\
\text { Retailer }\end{array}$ & Pricing, Service & $\begin{array}{l}\text { Manufacturer } 1 \text { Stackelberg, } \\
\text { Manufacturer } 2 \text { Stackelberg, } \\
\text { Manufacturer Stackelberg-- } \\
\text { Bertrand model }\end{array}$ & $\begin{array}{l}1 \text { Online, } \\
1 \text { Retail channel }\end{array}$ \\
\hline Jafari et al. $[17]$ & $\begin{array}{l}1 \text { Manufacturer, } \mathrm{K} \\
\text { Retailer }\end{array}$ & Pricing & $\begin{array}{l}\text { Vertical Nash, Strategic } \\
\text { alliance }\end{array}$ & $\begin{array}{l}1 \text { Online, } \\
\text { K Retail channel }\end{array}$ \\
\hline Matsui [25] & $\begin{array}{l}1 \text { Manufacturer, } 2 \\
\text { Retailer }\end{array}$ & Pricing & $\begin{array}{l}\text { Manufacturer Stackelberg, } \\
\text { Vertical Nash }\end{array}$ & 2 Retail channel \\
\hline Li et al. $[21]$ & $\begin{array}{l}1 \text { Manufacturer, } 1 \\
\text { Retailer }\end{array}$ & $\begin{array}{l}\text { Pricing, Service, } \\
\text { Showrooming effort }\end{array}$ & $\begin{array}{l}\text { No service effort, Ex-ante } \\
\text { service effort, Ex-post service } \\
\text { effort }\end{array}$ & $\begin{array}{l}1 \text { Online, } \\
1 \text { Retail channel }\end{array}$ \\
\hline This paper & $\begin{array}{l}1 \text { Manufacturer, } 2 \\
\text { Retailer }\end{array}$ & $\begin{array}{l}\text { Pricing, Manufacturer } \\
\text { service }\end{array}$ & $\begin{array}{l}\text { Manufacturer Stackelberg, } \\
\text { Strategic alliance, No improved } \\
\text { service }\end{array}$ & $\begin{array}{l}1 \text { Online, } \\
2 \text { Retail channel }\end{array}$ \\
\hline
\end{tabular}

the manufacturer sells products to the retailers at wholesale price $w$. After that the retailers, R1 and R2 sell the products to the customers at retail prices $p_{r 1}$ and $p_{r 2}$ respectively. After purchasing the products if any customers need some help regarding the products, e.g., free installation service, warranty service, etc., then the manufacturer will give the services directly to the customers. The manufacturer provides services $s_{r 1}$ and $s_{r 2}$ for the products which are sold through the retail channels $\mathrm{R} 1$ and $\mathrm{R} 2$ respectively. We assume that the services, provided by the manufacturer, effect linearly on the demands of the retail channels. Let the efficacy of the services $s_{r 1}$ and $s_{r 2}$ are $\lambda_{2}$ and $\lambda_{3}$ respectively. The service will give more contribution to the demand rate if the values of both $\lambda_{2}$ and $\lambda_{3}$ increase. The cost of the manufacturer for providing services are $c\left(s_{r 1}\right)=\frac{1}{2} \eta_{2} s_{r 1}^{2}$ and $c\left(s_{r 2}\right)=\frac{1}{2} \eta_{3} s_{r 2}^{2}$, obtained from Yan and Pei [41] and Zhao and Wang [45]. We consider that the demand functions are linearly dependent on the prices $[9,17]$ ) and the services [46]. In this model, we consider that same channel pricing decisions have a negative effect on the demand rates and have positive effects on the cross-channel pricing decisions. It is also assumed that the own channel service has positive effects on the customers' demand.

Therefore the demand rates of the two retailer channels are as follows:

$\mathrm{R} 1: d_{r 1}=\beta_{1}-p_{r 1}+\theta p_{r 2}+\lambda_{2} s_{r 1}$,

$\mathrm{R} 2: d_{r 2}=\beta_{2}-p_{r 2}+\theta p_{r 1}+\lambda_{3} s_{r 2}$,

where $0<\theta<1$ and $\beta_{1}(>0)$ and $\beta_{2}(>0)$ are the market potentials with respect to the $\mathrm{R} 1$ and $\mathrm{R} 2$ respectively.

For simplicity, we assume the production cost as 0 . Therefore the profit of the retailers $\mathrm{R} 1$ and $\mathrm{R} 2$ are determined by $\Pi_{r 1}=\left(p_{r 1}-w\right) d_{r 1}$ and $\Pi_{r 2}=\left(p_{r 2}-w\right) d_{r 2}$ respectively. The profit of the manufacturer is determined by $\Pi_{m}=w\left(d_{r 1}+d_{r 2}\right)-\frac{1}{2}\left(\eta_{2} s_{r 1}^{2}+\eta_{3} s_{r 2}^{2}\right)$.

Now, if the retailers and the manufacturer form a strategic alliance, then the total profit of the supply chain would be $\Pi_{A}=\Pi_{m}+\Pi_{r 1}+\Pi_{r 2}$.

The summary of useful notation for this model formulation is in Table 2. 


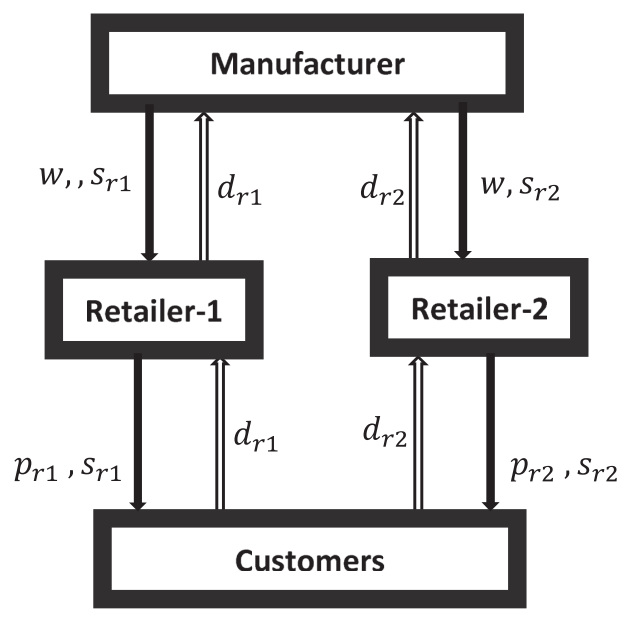

FigURE 1. DCSC without direct channel. Descriptions of the symbols used in the figure are given in Table 2.

TABLE 2. Notation of the model.

\begin{tabular}{ll}
\hline \hline Notation & Explanations \\
\hline$p_{d}, p_{r 1}$ and $p_{r 2}$ & Selling prices of the direct, R1 and R2 channels respectively (\$ per unit) \\
$w$ & Wholesale prices (per unit) \\
$d_{1}, d_{r 1}$ and $d_{r 2}$ & Demand rates of the direct, R1 and R2 channels respectively (per unit time) \\
$\eta_{1}, \eta_{2}$ and $\eta_{3}$ & Service cost of the given services $(\$)$ \\
$\theta$ & Positive cross-channel pricing effects; $\theta \in(0,1)$ \\
$\Pi_{m}, \Pi_{r 1}$ and $\Pi_{r 2}$ & Profits (\$) of the manufacturer, R1 and R2 respectively \\
$\Pi_{c}$ & Total supply chain profit (\$) \\
$\lambda_{1}, \lambda_{2}$ and $\lambda_{3}$ & Positive effect of the manufacturer's service on the demand rate (per unit time) \\
\hline
\end{tabular}

Now, we characterize all the optimal decisions for the retailers and the manufacturer under the described model in the SS and SA.

\subsubsection{Stackelberg model framework}

In the Stackelberg competition model, firstly, the manufacturer makes his decision to set wholesale prices and services to maximize his profit. Then the retailers set their selling prices to optimize their profit (see Fig. 2). That is, in this setting, the manufacturer acts as a leader, and the two retailers are the followers. The complete characteristics of the optimal decisions for the manufacturer and the retailers along with solution procedure are provided in the Table B.1.

\subsubsection{Strategic alliance}

In SA, the manufacturer and the retailers make decisions together to pursue mutual benefits. The overall characteristics of the optimal decision variables for each player are listed in Table C.1 with the total solution procedure.

\subsection{Direct channel (DC) added by the manufacturer}

Now, the DC is added to the supply chain in which the manufacturer sells products directly to the customers (see Fig. 3). Let us assume that the manufacturer sets selling price $p_{1}$ and the services $s_{d}$ for the DC. 


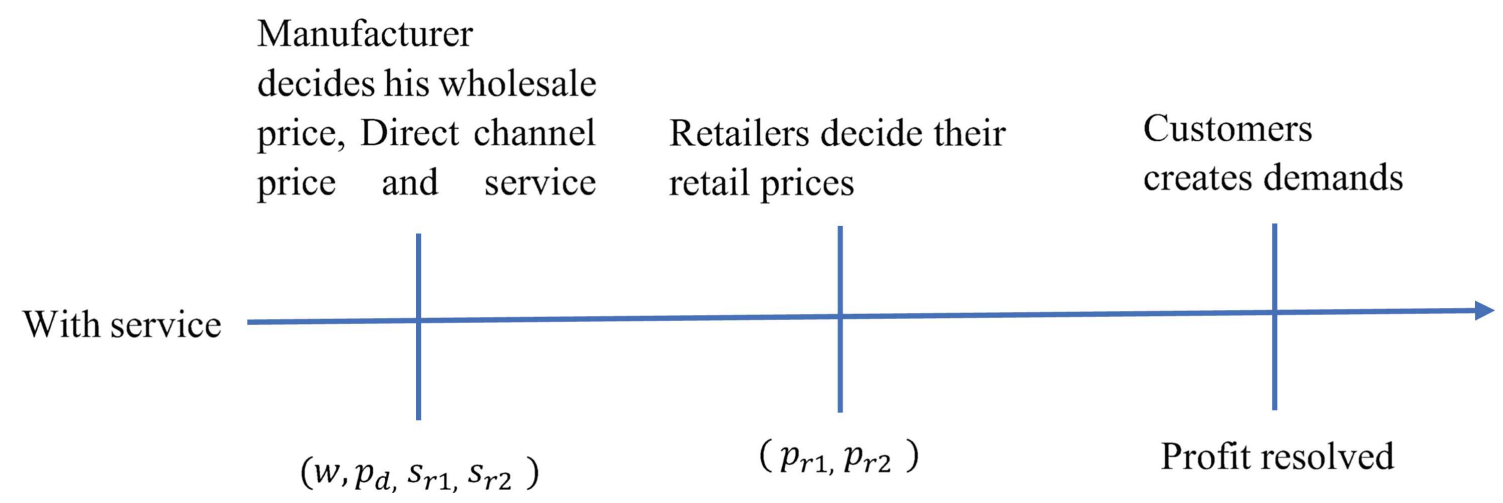

FiguRE 2. The sequence of determining the decision variables under SS.

Now, we discuss the MCSC containing one direct channel and two indirect channels [41]. For each channel, the corresponding demand rates for products are as follows:

DC: $d_{1}=\alpha_{1}-p_{d}+\theta\left(p_{r 1}+p_{r 2}\right)+\lambda_{1} s_{d}$,

$\mathrm{R} 1: d_{r 1}=\alpha_{2}-p_{r 1}+\theta\left(p_{d}+p_{r 2}\right)+\lambda_{2} s_{r 1}$ and

$\mathrm{R} 2: d_{r 2}=\alpha_{3}-p_{r 2}+\theta\left(p_{d}+p_{r 1}\right)+\lambda_{3} s_{r 2}$,

where $0<\theta<1 ; \alpha_{1}, \alpha_{2}$ and $\alpha_{3}$ are the market potentials with respect to the direct channel, R1 and R2 respectively.

Consequently, the profit of the $\mathrm{R} 1$ is determined by

$$
\Pi_{r 1}=\left(p_{r 1}-w\right) d_{r 1}
$$

and the profit of the $\mathrm{R} 2$ is determined by

$$
\Pi_{r 2}=\left(p_{r 2}-w\right) d_{r 2} .
$$

Now, the profit of the manufacturer is as follows:

$$
\Pi_{m}=p_{d} d_{1}+w\left(d_{r 1}+d_{r 2}\right)-\frac{1}{2}\left(\eta_{1} s_{d}^{2}+\eta_{2} s_{r 1}^{2}+\eta_{3} s_{r 2}^{2}\right) .
$$

Therefore the total profit of the players is as follows:

$$
\Pi_{c}=\Pi_{r 1}+\Pi_{r 2}+\Pi_{m} .
$$

Now, this model is analyzed in three directions: SS, SA and no improved service (NIS). The sequence of the manufacturer and the retailer determining their control variables of SS are explained below:

(1) Firstly, manufacturer sets the wholesale price $(w)$, direct channel price $\left(p_{d}\right)$ and service levels $\left(s_{d}, s_{r 1}\right.$ and $\left.s_{r 2}\right)$ to maximize its own profit.

(2) Then, considering the decisions of manufacturer, the retailers determine their selling prices $\left(p_{r 1}\right.$ and $\left.p_{r 2}\right)$ to optimize their profits.

In $\mathrm{SA}$, the players decide the values of the control variables $\left(p_{r 1}, p_{r 2}, s_{d}, s_{r 1}, s_{r 2}\right)$ of the total channel's profit (3.5) all together to maximize the total profit. NIS means: the service provided by the manufacturer whenever the direct channel has not been introduced. In NIS, two subcases are discussed. In the first subcase, the service valued of retailers are taken from SS model in Section 3.1.1 and the same is taken from SA model in Section 3.1.2 for second subcase. 


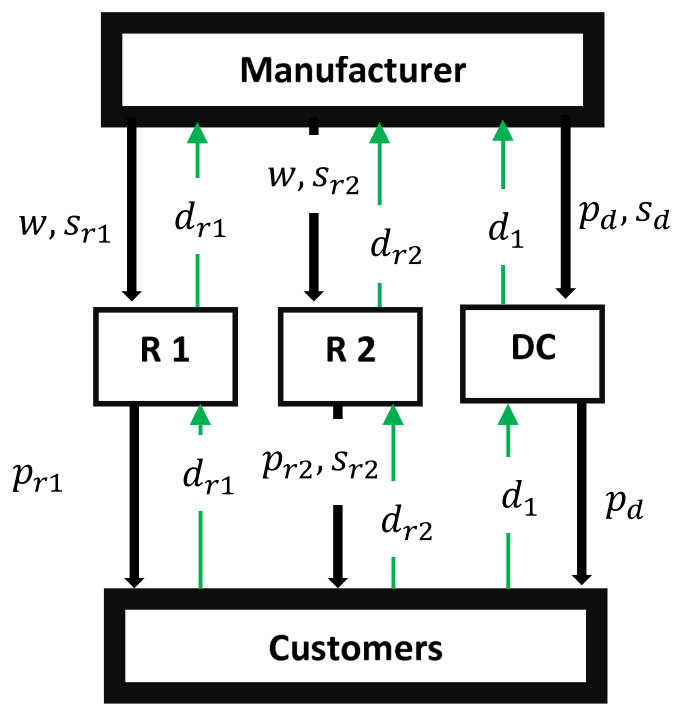

FiguRE 3. Multi-channel supply chain.

\subsubsection{Stackelberg setting}

Now, we discuss about the optimal decision variables for each players of the supply chain in SS. The optimal pricing variables, demand rates, services provided by the manufacturer and profit functions are obtained from (3.1) to (3.4) and listed in the Table B.2.

\subsubsection{Strategic alliance}

In SA, from (3.1) to (3.3), the total profit is

$$
\begin{aligned}
\Pi_{c} & =\Pi_{m}+\Pi_{r 1}+\Pi_{r 2} \\
& =p_{r 1} d_{r 1}+p_{r 2} d_{r 2}+p_{d} d_{1}-\frac{1}{2}\left(\eta_{1} s_{d}^{2}+\eta_{2} s_{r 1}^{2}+\eta_{3} s_{r 2}^{2}\right) .
\end{aligned}
$$

Then the optimal pricing decisions, demand rates, services given by the manufacturer, the total profit of the supply chain are obtained from (3.5) and noted down in Table C.2.

\subsection{No improved service}

Now, we consider a channel competition with NIS and study about the impact on the profits of the manufacturer and the retailers in Stackelberg setting. Here, we introduce two types of constant non-improved services: NIS form I (NS1) and NIS form II (NS2).

\subsubsection{NIS form I (NS1)}

In this subsection, we treat the manufacturer service as constant and the values are taken from the DCSC without direct channel under SS, i.e., $s_{r 1}=\frac{\left(\beta_{1}+\beta_{2}\right) \eta_{3} \lambda_{2}}{\eta_{3} \lambda_{2}^{2}+\eta_{2}\left(4 \eta_{3}\left(2-3 \theta+\theta^{2}\right)-\lambda_{3}^{2}\right)}$ and $s_{r 2}=\frac{\left(\beta_{1}+\beta_{2}\right) \eta_{2} \lambda_{3}}{\eta_{3} \lambda_{2}^{2}+\eta_{2}\left(4 \eta_{3}\left(2-3 \theta+\theta^{2}\right)-\lambda_{3}^{2}\right)}$ (from the Tab. B.1). In Appendix D, the solution procedure of this case is discussed and then optimal pricing decisions, profits of the manufacturer and the retailers under SS are summarized in the Table D.1.

\subsubsection{NIS form II (NS2)}

In this subsection, we consider the services as constants and the values are as follows: $s_{r 1}=s_{r 1}^{\mathrm{NC}}$ and $s_{r 2}=s_{r 2}^{\mathrm{NC}}$ (from Tab. C.1). Then optimal pricing decisions for each players, profits of the manufacturer and the retailers under SS using the equations (3.1) to (3.3) are listed in the Table D.2. 


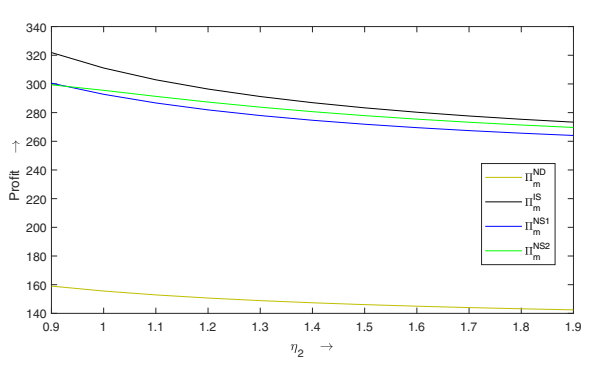

(a)

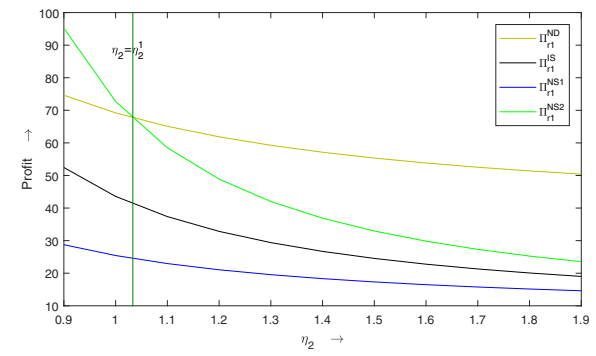

(b)

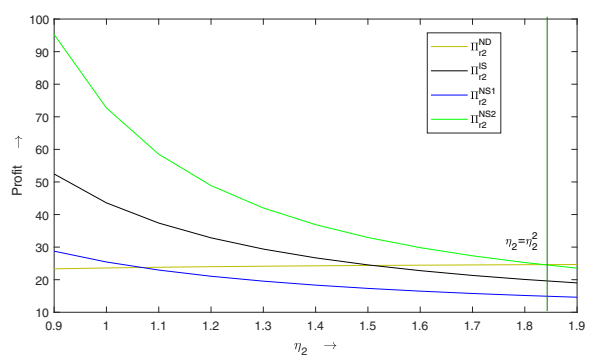

(c)

$$
\eta_{1}=2.6, \eta_{3}=1.75, \lambda_{1}=0.6, \lambda_{2}=0.85, \lambda_{3}=0.95, \theta=0.28
$$

FiguRE 4. Effect of $\eta_{2}$ on the profit of each player under different cases. (a) The profit functions of the manufacturer. (b) The profit functions of the R1. (c) The profit functions of the R2.

\section{Sensitivity AnAlysis}

In this section, we compare the profits of each player of the supply chain, the total profits of the supply chain under four cases such as SS, SA, two types of NIS (NS1 and NS2). We analyze the sensitivities with the help of the software "Wolfram Mathematica 9". We study the effects of $\eta_{i}, \lambda_{i}$ and $\theta$ on the profit functions, where $i=1,2,3$. We initialize some parameters as follows: $\alpha_{1}=15, \alpha_{2}=10, \alpha_{3}=9, \beta_{1}=20, \beta_{2}=14$.

\subsection{Effect of $\eta_{2}$}

Now, we analyze the effect of $\eta_{2}$ on the profit of each players of MCSC. At first we analyze the profit function of the manufacturer and then R1 and R2.

\subsubsection{Profit of the players of the MCSC}

Here, we compare the profits of players under four different cases in MCSC. The cases are as follows:

(1) MCSC with improved service level (case-IS).

(2) MCSC for the case-NS1.

(3) MCSC for the case-NS2.

(4) DCSC without direct channel (case-ND).

Observation 4.1. In Figure 4, we observe the following facts:

(1) The profit of the manufacturer is highest in the case-IS (see Fig. 4a).

(2) In Figure $4 \mathrm{~b}$, there exist a certain $\eta_{2}^{1}$ such that,

(a) whenever $\eta_{2} \leqslant \eta_{2}^{1}$, the profit of the R1 is maximum under the case-NS2;

(b) whenever $\eta_{2}^{1} \leqslant \eta_{2}$, then the profit of the R1 is maximum under the case-ND. 
(3) For the profit of the R2, in Figure 4c, there exist a fixed quantity $\eta_{2}^{2}$ such that,

(a) in the case-NS2 is higher than any other cases whenever $\eta_{2} \leqslant \eta_{2}^{2}$;

(b) in the case-ND is higher than other cases whenever $\eta_{2}^{2} \leqslant \eta_{2}$.

Moreover, slopes of all the profit functions for each player are in downward direction except for the profit function of R2 under the case-ND.

Whenever the cost of the services increases, it affects directly the profit of the manufacturer. So the sloping direction of all the profit functions of the manufacturer is in the downward direction. The profit of the manufacturer is highest under the case-IS as in the case-IS, the manufacturer leads the channel and the retailers follow him/her. Therefore, with the increasing $\eta_{2}$, he/she adjusts the decisions in such a way that the effect of increasing costs with service of R1 does not suffer so much on his/her profit.

When the value of $\eta_{2}$ is lower than some fixed quantity $\eta_{2}^{1}$, the profit of the retailer is maximum under the case-NS2 as the value of the $s_{r 1}$ is a constant which is taken from the case 3.3.2. So that the manufacturer leadership decisions do not make bad effects very much for the lower value of $\eta_{2}$. But whenever $\eta_{2}$ increases, the rate of decrement of the profit under the case is greater than any other. So after $\eta_{2}$ crosses a certain value $\eta_{2}^{1}$, the profit of R1 under the case-ND becomes greater than the case NS2. A similar case occurs for the R2. The profit function of the R2 under the case-ND decreases very slowly with the increment of $\eta_{2}$. Because in the case-ND, the direct channel is not present there. So in the supply chain, there exist only R1 and R2. Whenever, the cost of service provided to R1 increases, then the manufacturer makes some move to retain his own profit. So, the negative effect of all these diereses the demand rate of $\mathrm{R} 1$ so that the demand rate of $\mathrm{R} 2$ increases.

\subsection{Effect of $\eta_{3}$}

The parameter $\eta_{3}$ is the service cost coefficient of the manufacturer in the channel R2. Now, we analyze the effect of $\eta_{3}$ on the profit of each players of the MCSC.

\subsubsection{Profit of the players of the MCSC}

Now, we plot the curves which represent the profit functions of the each players of the MCSC. Then we observe the effect of $\eta_{3}$ on them.

Observation 4.2. In Figure 5, we observe the following facts:

(1) The manufacturer makes a maximum profit in the case-IS and his profit decreases with the increment of $\eta_{3}$ for all the cases (see Fig. 5a).

(2) The profit of R1 and R2 is maximum for the same case-NS2. For all the cases, the R1's profits increases with the increment of $\eta_{3}$ (see Fig. 5b) but the profit functions of $\mathrm{R} 2$ are downward sloping (see Fig. 5c).

In Figure 5a, the profit is the maximum for the manufacturer under the case-IS. Since, only, in this case, the manufacturer has provided improved service. As a result, the demand rates and consequently the profits of the manufacturer are higher than the other cases. Consequently, the profit of the manufacturer is higher than in other cases. But, if the service cost coefficient with respect to the service $s_{r 2}\left(\eta_{3}\right)$ increases, then it has an indirect effect on the demand rates of the channels and a direct effect on the manufacturer's profit functions. So the profits of the manufacturer move downward direction with the increment of $\eta_{3}$. But, whenever $\eta_{3}$ increases, the manufacturer decided to give less service to channel $\mathrm{R} 2$. Therefore, the demand rate of the channel R2 decreases and consequently its affects positively the profits of the R1. Therefore the curve of profits moves upward direction with the increment of $\eta_{3}$. In the case-NS2, all the players make the decision together to maximize their individual profits. But except this, the manufacturer is the leader for all other cases. So the Manufacturer firstly thinks about his profits. Consequently, the service provided by his become lesser with the increment of service cost. As a result, the demand rate and consequently the profit fallen down for R2. Therefore, the profit of $\mathrm{R} 2$ decreases as $\eta_{3}$ increases. 


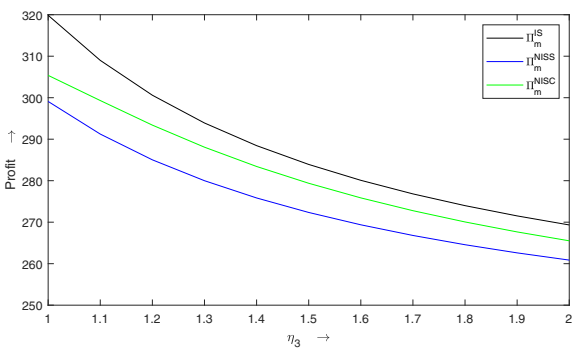

(a)

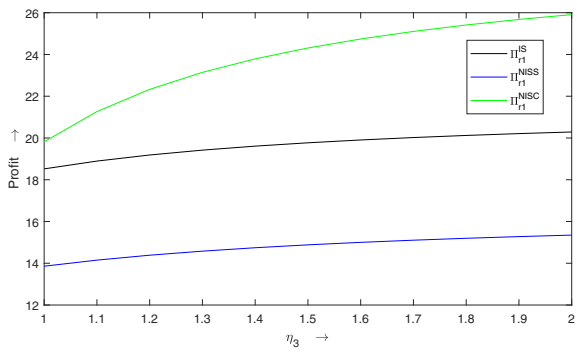

(b)

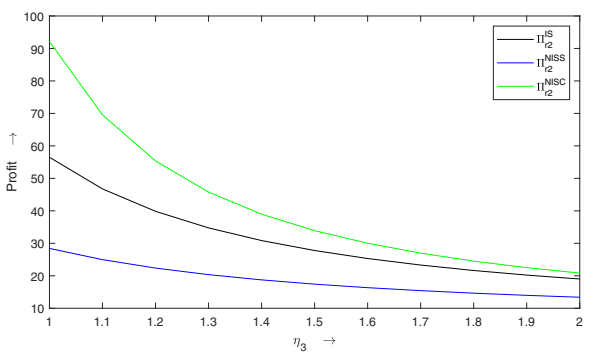

(c)

$$
\eta_{1}=2.6, \eta_{3}=1.75, \lambda_{1}=0.6, \lambda_{2}=0.85, \lambda_{3}=0.95, \theta=0.28
$$

FiguRE 5. Effect of $\eta_{3}$ on the profit of each player under different cases. (a) The profit functions of the manufacturer. (b) The profit functions of the R1. (c) The profit functions of the R2.

\subsection{Effect of $\eta_{1}$}

Now, we analyze the effect of $\eta_{1}$ on the profit of each players of the MCSC. At first we analyze the profit function of the manufacturer.

\subsubsection{Profit of the players of the MCSC}

Here, we compare the profits of manufacturer under four different cases in MCSC.

Proposition 4.3. In the Figure 6, we can observe the following:

(1) The profit of the manufacturer under the case-IS is greater than any other case (see Fig. 6a).

(2) The profits of the $R 1$ and $R 2$ are remains almost constant with the variation of $\eta_{1}$.

In Figure 6, it can also be observed that all the slopes of the profit functions are in a downward direction as $\eta_{1}$ increases. But the changes in the profits are very small. That is why we can conclude that the effect of $\eta_{1}$ is negligible on the profits of the players in $M C S C$.

\subsubsection{Effect of $\eta_{1}, \eta_{2}$ and $\eta_{3}$ on total profits of the supply chain under different cases}

In Figures $7 \mathrm{a}-7 \mathrm{c}$, we plot the curves which represent the total profit of the supply chain under several cases such as:

(1) DCSC without direct channel in SS $\left(\Pi_{T}^{\mathrm{ND}}\right)$.

(2) DCSC without direct channel in SA $\left(\Pi_{c}^{\mathrm{ND}}\right)$.

(3) MCSC with improved service in SS $\left(\Pi_{T}^{\mathrm{IS}}\right)$.

(4) NS1 $\left(\Pi_{T}^{\mathrm{NS} 1}\right)$.

(5) NS2 $\left(\Pi_{T}^{\mathrm{NSS} 2}\right)$. 


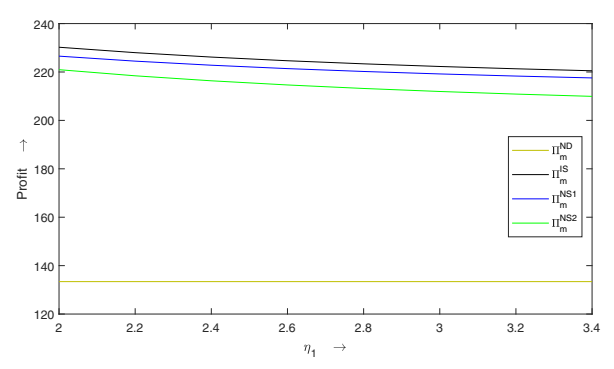

(a)

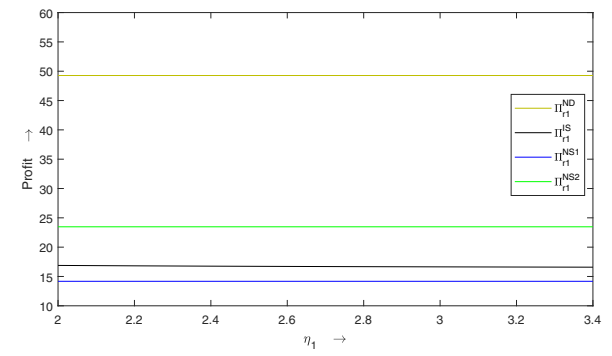

(b)

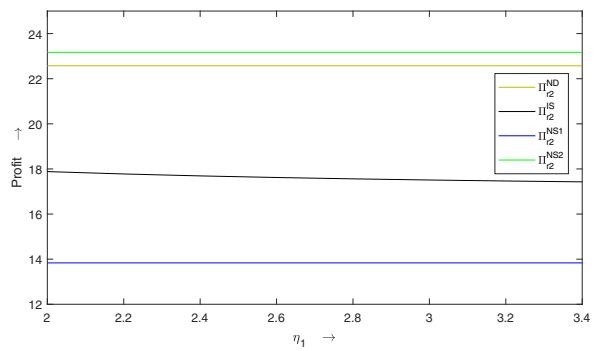

(c)

$$
\eta_{2}=3, \eta_{3}=1.75, \lambda_{1}=0.6, \lambda_{2}=0.85, \lambda_{3}=0.95, \theta=0.25
$$

FiguRE 6. Effect of $\eta_{1}$ on the profit of each player under different cases for different valued of $\theta$. (a) The profit functions of the manufacturer. (b) The profit functions of the R1. (c) The profit functions of the R2.

(6) MCSC with improved service in SA $\left(\Pi_{c}^{\mathrm{IS}}\right)$.

From Figure 7, we conclude a result as follows:

Observation 4.4. In each case, the profit function is decreasing with an increment of $\eta_{2}$. But the total profit of the MCSC under SA with improved service dominates all other cases. The lowest profit of the supply chain is whenever the direct channel is absent in SS. The profit of the DCSC is lower under SS than any other case.

It is obvious that if service cost increases, then the service provider has two options. Firstly, he can reduce his service level and secondly, he can raise the selling price of the products. In each case, the demand rates of supply chain decrease, so that the total profit of the supply chain decreases. Again in SA, players take their decisions in such a way that they can get more profit mutually and the improved service makes a better impact on the customers. So the total profits under the case MCSC with improved service under SA are maximized. We know that the total profit of a supply chain under SA is higher than the SS. So the total profits of the dual-channel supply chain under Stackelberg settings are lowest. As we can see in Figures 7a and 7c, same results occur whenever we increase the value of $\eta_{1}$ and $\eta_{3}$.

\subsection{Effect of $\lambda_{1}$}

The parameter $\lambda_{1}$, coefficient of the service offered by the manufacturer to the direct channel, has a positive effect on the demand function. It would depend on the service quality level, the behaviors of the service provider, etc. Now, we discuss the effect of the parameter $\lambda_{1}$ on the profit of the players in the supply chain. 


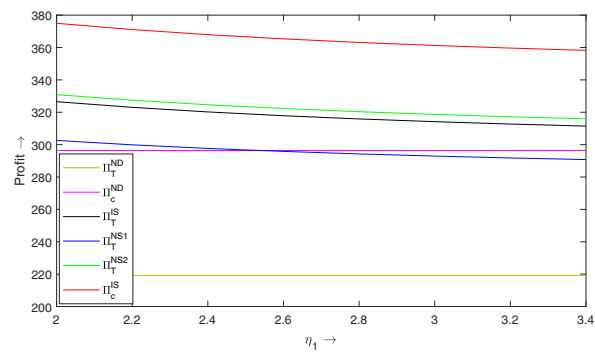

(a)

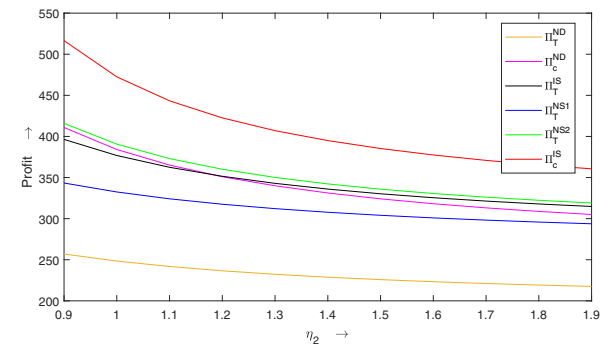

(b)

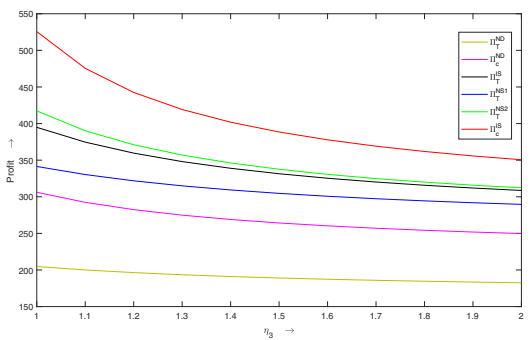

(c)

$$
\lambda_{1}=0.6, \lambda_{2}=0.85, \lambda_{3}=0.95, \theta=0.28
$$

FiguRE 7. Effects of $\eta_{2}$ and $\eta_{3}$ on the total profit under different cases. (a) Total profit of the supply chain with different values of $\eta_{1}$ and $\eta_{2}=1.8, \eta_{3}=1.75$. (b) Total profit of the supply chain with different values of $\eta_{2}$ and $\eta_{1}=2.6, \eta_{3}=1.75$. (c) Total profit of the supply chain with different values of $\eta_{3}$ and $\eta_{1}=2.6, \eta_{2}=1.8$.

\subsubsection{On the profit of the players of the MCSC}

Now, we plot the curves of the profit functions of each player in Figure 8 to study the sensitivity of $\lambda_{1}$ on the profits of the players of the MCSC.

Observation 4.5. From Figure 8, we can argue as follows:

(1) In Figure 8a, the profit of the manufacturer in the case-IS is higher than the other cases. It is also clear that, in all cases, the profit of the manufacturer increases with the increment of $\lambda_{1}$.

(2) The profit of the R1 under the cases-NS1 and NS2 are fixed by the change of $\lambda_{1}$ (see Fig. 8b).

(3) The R2's profit under cases-NS1 and NS2 are fixed, but under the case-IS is increasing with the increment of $\lambda_{1}$ (see Fig. 8c).

The parameter $\lambda_{1}$ is the service coefficient of the demand rate in the direct channel. That is, whenever $\lambda_{1}$ increases, the demand rate increases. Therefore, the profit of the manufacturer will be increased through the direct channel. Hence the total profit directed upwards whenever $\lambda_{1}$ increases. Now, from Figure 8a, we can conclude that the maximum profit that the manufacturer can get is in the case-IS. Because in this case, the manufacturer service is improved and consequently, the demand rate increases. As a result, the profit of the manufacturer is maximally compared to other cases. But the profit of the R1 under the cases-NS1 and NS2 remains fixed with the changing parameter $\lambda_{1}$ (Fig. 8b). Because firstly, the channel R1 does not directly depend on this parameter and secondly, the manufacturer service is also not improved in these two cases. So, there is no effect of the changing parameter $\lambda_{1}$ on the profit functions of R1 under the cases-NS1 and NS2. For a similar region, the profits of the $\mathrm{R} 2$ remain unchanged with the parameter $\lambda_{1}$. 


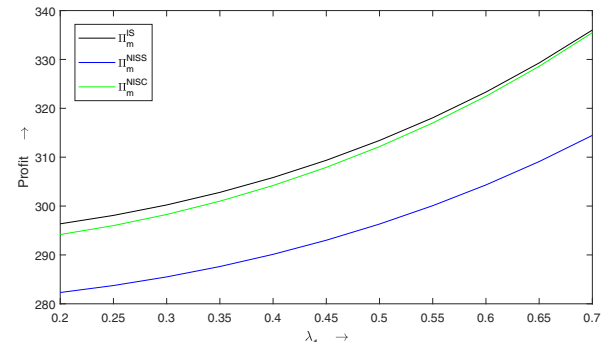

(a)

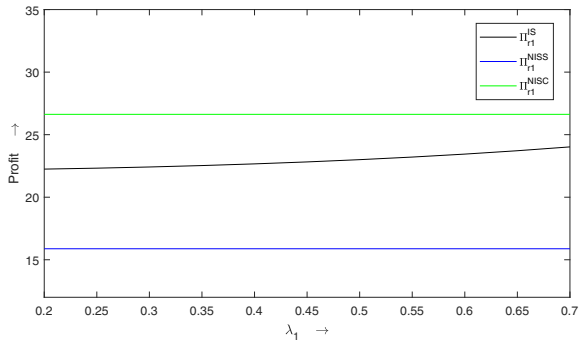

(b)

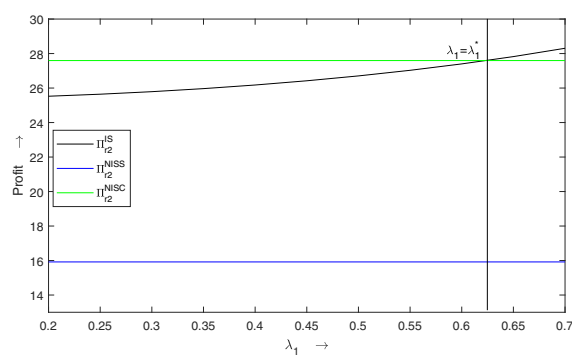

(c)

$$
\eta_{1}=2.6, \eta_{2}=1.8, \eta_{3}=1.75, \lambda_{2}=0.85, \lambda_{3}=0.95, \theta=0.28
$$

FiguRE 8. Effect of $\lambda_{1}$ on the profit of each player under different cases. (a) The profit functions of the manufacturer. (b) The profit functions of the R1. (c) The profit functions of the R2.

\subsection{Effect of $\lambda_{2}$ and $\lambda_{3}$}

The parameters $\lambda_{2}$ and $\lambda_{3}$ are the positive effect on the demand of the service given by the manufacturer to the R1 and R2 channels respectively. Now, we discuss the effect of the parameters $\lambda_{2}$ and the $\lambda_{3}$ on the profit of the players in the supply chain separately.

\subsubsection{The profit of the players of the MCSC}

Now, we analyze the sensitivity of $\lambda_{2}$ and $\lambda_{3}$ on the players of the MCSC.

Observation 4.6. From the Figures 9 and 10, we can conclude some results as follows:

(1) In Figures 9a and 10a, it is clear that, in all cases, the profit of the manufacturer increases with the increment of $\lambda_{2}$ and $\lambda_{3}$.

(2) The profit of the $\mathrm{R} 1$ is increasing with the increment of the parameter $\lambda_{2}$ but decreasing with the increment of $\lambda_{3}$ under all cases (see Figs. 9b and 10b).

(3) The profit of The R2 is increasing with the increment of $\lambda_{3}$ and decreasing with the increment of $\lambda_{2}$ under all the cases (see Figs. 9c and 10c)

The parameters $\lambda_{2}$ and $\lambda_{3}$ are the coefficient of the services given by the manufacturer to the R1 and R2 in the demand functions respectively. Whenever $\lambda_{2}$ or $\lambda_{3}$ increases, the positive effect of the services increases but service cost remains unchanged. So that the demand rate increases and consequently the profits of the manufacturer increase in each case. Similarly, if $\lambda_{2}$ increases, the demand rate of the channel-R1 increases and consequently the manufacturer wishes to increase the service. Whenever the manufacturer gives more service to the supply chain channels, the selling price of each channel also increases. That is, the increment of the parameter $\lambda_{2}$ has both positive and negative effects on each channel. Since $\lambda_{2}$ directly increases its demand 


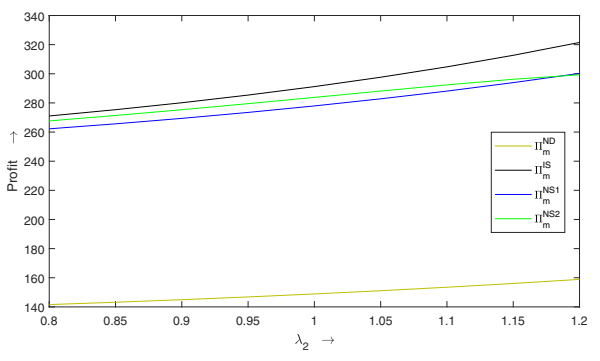

(a)

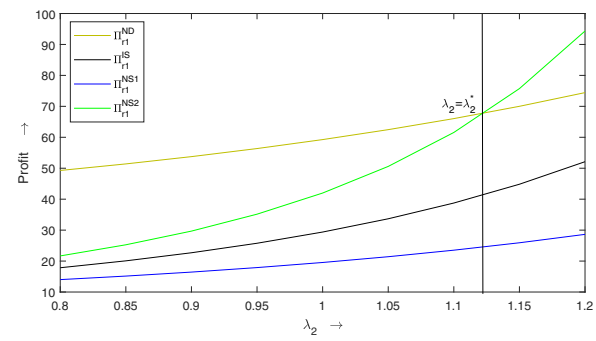

(b)

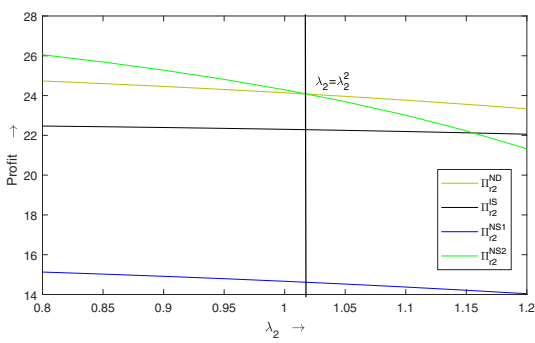

(c)

$$
\eta_{1}=2.6, \eta_{2}=1.8, \eta_{3}=1.75, \lambda_{1}=0.6, \lambda_{3}=0.95, \theta=0.28
$$

FIGURE 9. Effect of $\lambda_{2}$ on the profit of each player under different cases. (a) The profit functions of the manufacturer. (b) The profit functions of the R1. (c) The profit functions of the R2.

rate so in this case, the positive effect is greater and consequently the profit of the channel R1 increases. But whenever $\lambda_{3}$ increases, the demand rate of the channel R1 is not affected directly. So the negative effect is more than the positive. Therefore the profit of the channel-R1 decreases with the increment of the value of $\lambda_{3}$ under each case. Similarly, we can describe for the channel R2.

\subsubsection{Effect of $\lambda_{1}, \lambda_{2}$ and $\lambda_{3}$ on the total profit of supply chain}

Now, we discuss the effect of the service coefficients of demand rates $\lambda_{1}, \lambda_{2}$ and $\lambda_{3}$ on the total profits of supply chains under different cases.

Observation 4.7. In Figure 11, it is shown that the total profit of MCSC increases with the increment of $\lambda_{1}, \lambda_{2}$ and $\lambda_{3}$ individually, i.e., taking two out of three as a fixed quantity, if the rest one is increased, then the total profit of the supply chain is also increased. The total profit of $\Pi_{c}^{\mathrm{IS}}$ is maximum in each of the cases.

The parameters $\lambda_{i}, i=1,2,3$ are the service coefficients of the demand rates of the direct channel, channel R1, and channel R2 respectively. If the parameter $\lambda_{1}$ increases, the demand rate for the direct channel increases, but the service cost retains the same for the manufacturer. As a result, the total profit of the supply chain increases. In SA, the total profit is always maximum than other strategies. So that in the case-IS, SA gives the most profit to the supply chain. For the same reason, For the increment of $\lambda_{2}$ and $\lambda_{3}$, the total profit functions also increasing under each case.

\subsection{Relation between $p_{d}$ and $w$ depending on $\eta_{2}$ and $\eta_{3}$}

In this section, we discuss the range of the two variables in which the direct channel price is less than the wholesale price. But in general, this is not possible. So that the service cost should have belonged to a certain interval. Now we consider the case-IS under the SS and the proposition is as follows: 


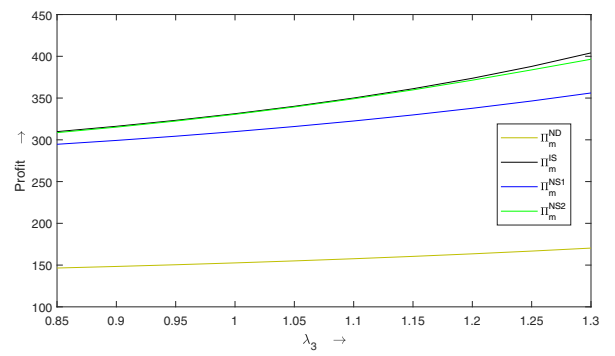

(a)

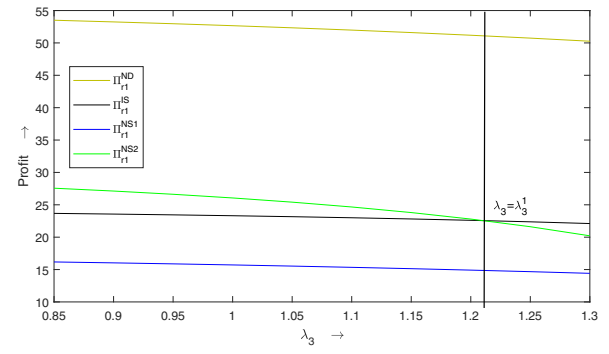

(b)

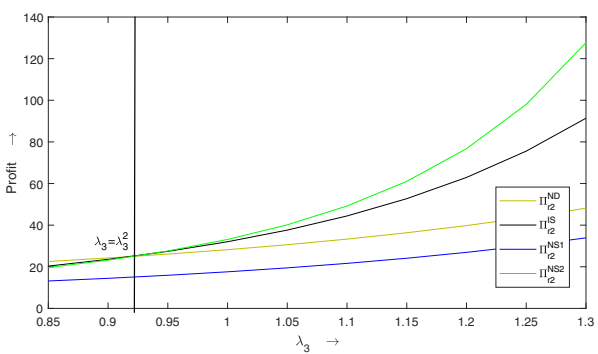

(c)

$$
\eta_{1}=2.6, \eta_{2}=1.8, \eta_{3}=1.75, \lambda_{1}=0.6, \lambda_{2}=0.85, \theta=0.3
$$

FiguRE 10. Effect of $\lambda_{3}$ on the profit of each player under different cases. (a) The profit functions of the manufacturer. (b) The profit functions of the R1. (c) The profit functions of the $\mathrm{R} 2$.

Proposition 4.8. In the case-IS under Stackelberg settings, we can find that if $\eta$ belongs to the interval $I=$ $\left[\min \left\{\eta_{2}^{1}, \eta_{2}^{1}\right\}, \max \left\{\eta_{2}^{1}, \eta_{2}^{1}\right\}\right]$, then the direct channel selling price become lesser than the wholesale price, where, $\eta_{2}^{1}=\frac{\alpha_{1} \eta_{1} \eta_{3}(1+\theta) \lambda_{2}^{2}}{\left(-\alpha_{2}-a_{3}\right) \eta_{3}(-2+\theta)\left(\eta_{1}(-2+4 \theta)+\lambda_{1}^{2}\right)+\alpha_{1} \eta_{1}\left(4 \eta_{3}\left(2-5 \theta+2 \theta^{2}\right)-(1+\theta) \lambda_{3}^{2}\right)}$ and $\eta_{2}^{2}=\frac{2 \eta_{1} \eta_{3} \lambda_{2}^{2}+4 \eta_{1} \eta_{3} \theta^{2} \lambda_{2}^{2}-\eta_{3} \lambda_{1}^{2} \lambda_{2}^{2}}{16 \eta_{1} \eta_{3}-24 \eta_{1} \eta_{3} \theta-24 \eta_{1} \eta_{3} \theta^{2}+16 \eta_{1} \eta_{3} \theta^{3}-8 \eta_{3} \lambda_{1}^{2}+12 \eta_{3} \theta \lambda_{1}^{2}-4 \eta_{3} \theta^{2} \lambda_{1}^{2}-2 \eta_{1} \lambda_{3}^{2}-4 \eta_{1} \theta^{2} \lambda_{3}^{2}+\lambda_{1}^{2} \lambda_{3}^{2}}$.

Proof. See Appendix A.

Now, we take a numerical example of the above Proposition 4.8.

In Figure 12, we can find out the possible value of $\eta_{2}$ such that the direct channel selling price is not less than the wholesale price. Similarly, we can find out the possible values of $\eta_{2}$ and $\eta_{3}$ under each case that should be avoided.

\section{Conclusion}

Increasing market competition is forcing companies/manufacturers to pay much more attention to satisfy customers. Generally, customers' satisfaction and their positive feedback increase when the original manufacturer provides service directly to the customers. As a result, the value of the product is upgraded in the market.

In this paper, the manufacturer service is introduced in the MCSC and also discussed the pricing decisions, servicing costs and corresponding profits of the players under SS, SA, and NIS. Furthermore, we analyze the sensitivity of parameters like service cost coefficients, the cross-channel pricing coefficients under different strategies. We also provide the relation between the direct channel price and the wholesale price which is a very helpful troop to make decisions for the manufacturer. The central outcomes of this paper are as follows: 


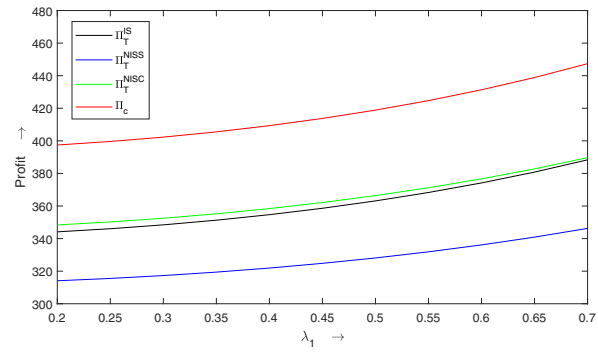

(a)

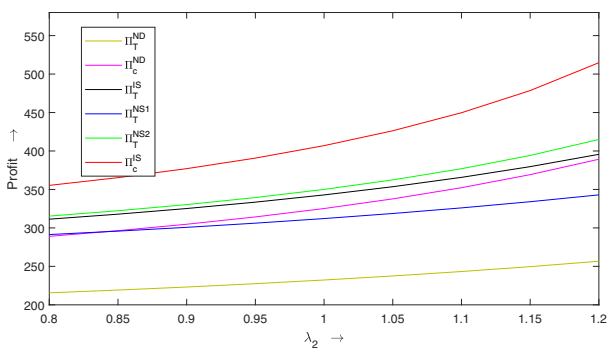

(b)

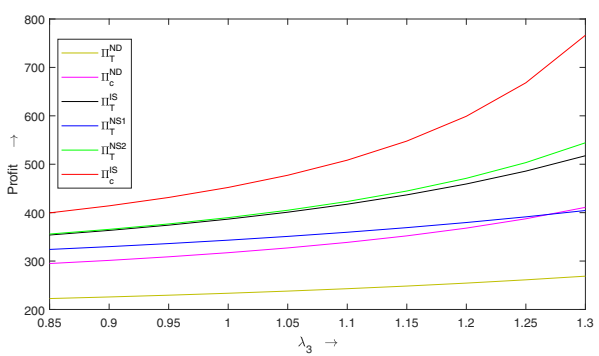

(c)

$$
\eta_{1}=2.6, \eta_{2}=1.8, \eta_{3}=1.75, \theta=0.28
$$

FigURE 11. Effect of $\lambda_{i}, i=1,2,3$ on the profit of each player under different cases. (a) Effect of $\lambda_{1}$. (b) Effect of $\lambda_{2}$. (c) Effect of $\lambda_{3}$.

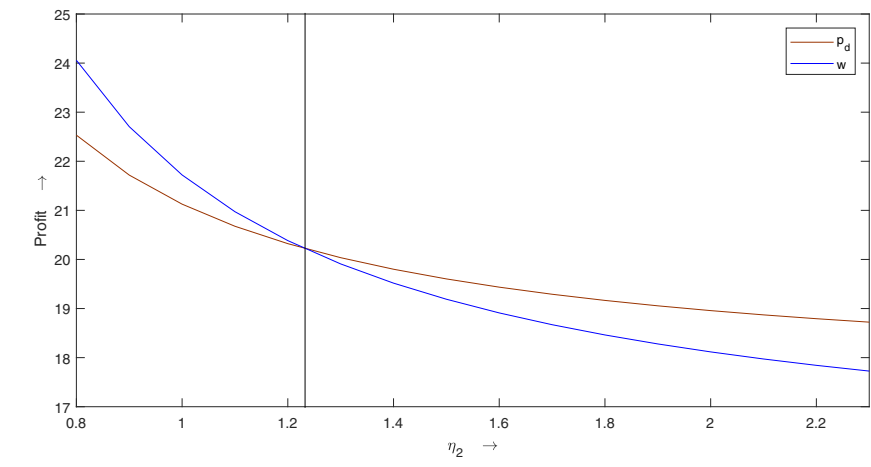

$$
\eta_{1}=2.6 \eta_{3}=1.75, \lambda_{1}=0.6, \lambda_{2}=0.85, \lambda_{3}=0.95, \theta=0.28
$$

Figure 12. Optimal values of $p_{d}$ and $w$.

(1) We observe the condition of the maximum profits of each of the players in the supply chain over the effects of the service costs and cross-channel price effects. These results will help the players to make decisions to make maximum profits. For example, if the Manufacturer gives lesser than a certain service, more profit gains.

(2) The wholesale price may not always be greater than the direct channel price. It is depending on the quality of the services. More specifically, if the Retailer channel gets better services than the direct channel, it can happen. 
(3) We consider two fixed manufacturer services $s^{\mathrm{NS}}$ and $s^{\mathrm{NC}}$ and with the help of these, we compute the pricing decisions of the chain and also compare the profits under different cases or strategies.

This paper has also some limitations. Firstly, we consider the deterministic and linear type demand function. Also, due to the complexity of the computation and sensitivity analysis, we consider the wholesale prices to both channel R1 and R2 as identical and constant.

Researchers can consider a probabilistic demand model with MCSC which may provide more insight into the MCSC. Secondly, One can consider that besides the manufacturer, the retailers also can provide services to the customers. Thirdly, one can consider the case where the manufacturer sets different wholesale prices for different retailers. Finally, another way to proceed is to consider the product quality level with the manufacturer's services.

Acknowledgements. The authors would like to express their gratitude to the editors and referees for their valuable suggestions and corrections to enhance the clarity of the present article. The first author also acknowledges the Council of Scientific \& Industrial Research, Government of India for financial assistance.

\section{Appendix A.}

From the Table B.2, we get the values of the direct channel selling price and wholesale price as follows:

$$
p_{d}=-\frac{\left(\eta_{1}\left(4\left(\alpha_{2}+\alpha_{3}\right) \eta_{2} \eta_{3}(-2+\theta) \theta+\alpha_{1}\left(\eta_{3} \lambda_{2}^{2}+\eta_{2}\left(-4 \eta_{3}\left(2-3 \theta+\theta^{2}\right)+\lambda_{3}^{2}\right)\right)\right)\right)}{\left(\lambda_{1}^{2}\left(\eta_{3} \lambda_{2}^{2}+\eta_{2}\left(-4 \eta_{3}\left(2-3 \theta+\theta^{2}\right)+\lambda_{3}^{2}\right)\right)+2 \eta_{1}\left(-\eta_{3}\left(1+2 \theta^{2}\right) \lambda_{2}^{2}+\eta_{2}\left(4 \eta_{3}\left(2-3 \theta-3 \theta^{2}+2 \theta^{3}\right)-\left(1+2 \theta^{2}\right) \lambda_{3}^{2}\right)\right)\right)} \text { and }
$$

$w=\frac{\left(-\alpha_{2} \eta_{2} \eta_{3}(-2+\theta)\left(2 \eta_{1}-\lambda_{1}^{2}\right)-\alpha_{3} \eta_{2} \eta_{3}(-2+\theta)\left(2 \eta_{1}-\lambda_{1}^{2}\right)+\alpha_{1} \eta_{1} \theta\left(\eta_{3} \lambda_{2}^{2}+\eta_{2}\left(8 \eta_{3}-4 \eta_{3} \theta+\lambda_{3}^{2}\right)\right)\right)}{\left(\lambda_{1}^{2}\left(\eta_{3} \lambda_{2}^{2}+\eta_{2}\left(-4 \eta_{3}\left(2-3 \theta+\theta^{2}\right)+\lambda_{3}^{2}\right)\right)+2 \eta_{1}\left(-\eta_{3}\left(1+2 \theta^{2}\right) \lambda_{2}^{2}+\eta_{2}\left(4 \eta_{3}\left(2-3 \theta-3 \theta^{2}+2 \theta^{3}\right)-\left(1+2 \theta^{2}\right) \lambda_{3}^{2}\right)\right)\right)}$ respectively.

Now $p_{d}-w=\frac{-\left(\alpha_{2}+a 3\right) \eta_{2} \eta_{3}(-2+\theta)\left(\eta_{1}(-2+4 \theta)+\lambda_{1}^{2}\right)+\alpha_{1} \eta_{1}\left(-\eta_{3}(1+\theta) \lambda_{2}^{2}+\eta_{2}\left(4 \eta_{3}\left(2-5 \theta+2 \theta^{2}\right)-(1+\theta) \lambda_{3}^{2}\right)\right)}{\lambda_{1}^{2}\left(\eta_{3} \lambda_{2}^{2}+\eta_{2}\left(-4 \eta_{3}\left(2-3 \theta+\theta^{2}\right)+\lambda_{3}^{2}\right)\right)+2 \eta_{1}\left(-\eta_{3}\left(1+2 \theta^{2}\right) \lambda_{2}^{2}+\eta_{2}\left(4 \eta_{3}\left(2-3 \theta-3 \theta^{2}+2 \theta^{3}\right)-\left(1+2 \theta^{2}\right) \lambda_{3}^{2}\right)\right)}$ Applying the condition $p_{d}-w<0$, we can conclude that $\eta_{2}$ belongs to a interval $I=\left[\min \left\{\eta_{2}^{1}, \eta_{2}^{1}\right\}, \max \left\{\eta_{2}^{1}, \eta_{2}^{1}\right\}\right]$ where,

$$
\begin{aligned}
\eta_{2}^{1} & =\frac{a 1 \eta_{1} \eta_{3}(1+\theta) \lambda_{2}^{2}}{\left(-\alpha_{2}-a 3\right) \eta_{3}(-2+\theta)\left(\eta_{1}(-2+4 \theta)+\lambda_{1}^{2}\right)+a 1 \eta_{1}\left(4 \eta_{3}\left(2-5 \theta+2 \theta^{2}\right)-(1+\theta) \lambda_{3}^{2}\right)} \text { and } \\
\eta_{2}^{2} & =\frac{2 \eta_{1} \eta_{3} \lambda_{2}^{2}+4 \eta_{1} \eta_{3} \theta^{2} \lambda_{2}^{2}-\eta_{3} \lambda_{1}^{2} \lambda_{2}^{2}}{16 \eta_{1} \eta_{3}-24 \eta_{1} \eta_{3} \theta-24 \eta_{1} \eta_{3} \theta^{2}+16 \eta_{1} \eta_{3} \theta^{3}-8 \eta_{3} \lambda_{1}^{2}+12 \eta_{3} \theta \lambda_{1}^{2}-4 \eta_{3} \theta^{2} \lambda_{1}^{2}-2 \eta_{1} \lambda_{3}^{2}-4 \eta_{1} \theta^{2} \lambda_{3}^{2}+\lambda_{1}^{2} \lambda_{3}^{2}} .
\end{aligned}
$$

\section{Appendix B. Solution Procedure under SS}

To maximize a real-valued function concerning its variables, firstly we have to solve the first-order conditions concerning the variables. Then it has to show that the Hessian matrix of the function is negative definite at the values of the variables. Then, the solution of the first-order conditions is the optimal values of the variables and using these values, we can obtain the optimal functional value. In Table B.1, we have listed the optimal values and corresponding profits. The solution procedure is discussed below:

(1) We solve the first order condition of the profit functions $\Pi_{r 1}$ and $\Pi_{r 2}$ with respect to $p_{r 1}$ and $p_{r 2}$ respectively.

(2) Putting the values of $p_{r 1}$ and $p_{r 2}$ in the profit function $\Pi_{m}$ and then solve the first order condition with respect to the variables $w, s_{r 1}$ and $s_{r 2}$ and let the obtained values are $w^{*}, s_{r 1}^{*}$ and $s_{r 2}^{*}$ respectively. If the Hessian matrix of the profit function $\Pi_{m}$ with respect to these three decision variables be negative definite, then $w^{*}, s_{r 1}^{*}$ and $s_{r 2}^{*}$ will be the optimal.

(3) Using the values of $w, s_{r 1}$ and $s_{r 2}$, we obtain the optimal values of $p_{r 1}$ and $p_{r 2}$ as $p_{r 1}^{*}$ and $p_{r 2}^{*}$ respectively.

(4) Putting the optimal values of the decision variables in the profit functions, we obtain the maximum profits of each player.

In similar fashion, we can obtain the optimal values of the decision variables when manufacturer added a direct channel and listed in Table B.2. 
TABLE B.1. Services, demand rates, firm profits and selling prices without any direct channel (SS).

\begin{tabular}{|c|c|}
\hline & Price \\
\hline Wholesale price: $w$ & $\frac{\left(\beta_{1}+\beta_{2}\right) \eta_{2} \eta_{3}(2-\theta)}{-\eta_{3} \lambda_{2}^{2}+\eta_{2}\left(4 \eta_{3}\left(2-3 \theta+\theta^{2}\right)-\lambda_{3}^{2}\right)}$ \\
\hline $\mathrm{R} 1: p_{r 1}$ & $\frac{\beta_{2} \eta_{3}\left(\eta_{2}\left(2+5 \theta-4 \theta^{2}\right)+\lambda_{2}^{2}\right)-\beta_{1} \eta_{2}\left(\eta_{3}(-10+7 \theta)+\lambda_{3}^{2}\right)}{(2+\theta)\left(-\eta_{3} \lambda_{2}^{2}+\eta_{2}\left(4 \eta_{3}\left(2-3 \theta+\theta^{2}\right)-\lambda_{3}^{2}\right)\right)}$ \\
\hline \multirow[t]{2}{*}{$\mathrm{R} 2: p_{r 2}$} & $\frac{\beta_{2} \eta_{3}\left(\eta_{2}(10-7 \theta)-\lambda_{2}^{2}\right)+\beta_{1} \eta_{2}\left(\eta_{3}\left(2+5 \theta-4 \theta^{2}\right)+\lambda_{3}^{2}\right)}{(2+\theta)\left(-\eta_{3} \lambda_{2}^{2}+\eta_{2}\left(4 \eta_{3}\left(2-3 \theta+\theta^{2}\right)-\lambda_{3}^{2}\right)\right)}$ \\
\hline & Services \\
\hline $\mathrm{R} 1: s_{r 1}^{\mathrm{ND}}$ & $\frac{\left(\beta_{1}+\beta_{2}\right) \eta_{3} \lambda_{2}}{\eta_{3} \lambda_{2}^{2}+\eta_{2}\left(4 \eta_{3}\left(2-3 \theta+\theta^{2}\right)-\lambda_{3}^{2}\right)}$ \\
\hline \multirow[t]{2}{*}{$\mathrm{R} 2: s_{r 2}^{\mathrm{ND}}$} & $\frac{\left(\beta_{1}+\beta_{2}\right) \eta_{2} \lambda_{3}}{\eta_{3} \lambda_{2}^{2}+\eta_{2}\left(4 \eta_{3}\left(2-3 \theta+\theta^{2}\right)-\lambda_{3}^{2}\right)}$ \\
\hline & Demand \\
\hline $\mathrm{R} 1: d_{r 1}$ & $\frac{\beta_{2} \eta_{3}\left(\eta_{2}\left(-2+5 \theta-3 \theta^{2}\right)+\lambda_{2}^{2}\right)+\beta_{1} \eta_{2}\left(\eta_{3}\left(6-7 \theta+\theta^{2}\right)-\lambda_{3}^{2}\right)}{(2+\theta)\left(-\eta_{3} \lambda_{2}^{2}+\eta_{2}\left(4 \eta_{3}\left(2-3 \theta+\theta^{2}\right)-\lambda_{3}^{2}\right)\right)}$ \\
\hline $\mathrm{R} 2: d_{r 2}$ & $\frac{\beta_{2} \eta_{3}\left(\eta_{2}\left(6-7 \theta+\theta^{2}\right)-\lambda_{2}^{2}\right)+\beta_{1} \eta_{2}\left(\eta_{3}\left(-2+5 \theta-3 \theta^{2}\right)+\lambda_{3}^{2}\right)}{(2+\theta)\left(-\eta_{3} \lambda_{2}^{2}+\eta_{2}\left(4 \eta_{3}\left(2-3 \theta+\theta^{2}\right)-\lambda_{3}^{2}\right)\right)}$ \\
\hline & Profit \\
\hline Manufacturer: $\Pi_{m}^{\mathrm{ND}}$ & $\frac{\left(\beta_{1}+\beta_{2}\right)^{2} \eta_{2} \eta_{3}}{-2 \eta_{3} \lambda_{2}^{2}+2 \eta_{2}\left(4 \eta_{3}\left(2-3 \theta+\theta^{2}\right)-\lambda_{3}^{2}\right)}$ \\
\hline $\mathrm{R} 1: \Pi_{r 1}^{\mathrm{ND}}$ & $\frac{\left(\beta_{2} \eta_{3}\left(\eta_{2}\left(-2+5 \theta-3 \theta^{2}\right)+\lambda_{2}^{2}\right)+\beta_{1} \eta_{2}\left(\eta_{3}\left(6-7 \theta+\theta^{2}\right)-\lambda_{3}^{2}\right)\right)^{2}}{(2+\theta)^{2}\left(\eta_{3} \lambda_{2}^{2}+\eta_{2}\left(-4 \eta_{3}\left(2-3 \theta+\theta^{2}\right)+\lambda_{3}^{2}\right)\right)^{2}}$ \\
\hline $\mathrm{R} 2: \Pi_{r 2}^{\mathrm{ND}}$ & $\frac{\left(\beta_{2} \eta_{3}\left(\eta_{2}\left(6-7 \theta+\theta^{2}\right)-\lambda_{2}^{2}\right)+\beta_{1} \eta_{2}\left(\eta_{3}\left(-2+5 \theta-3 \theta^{2}\right)+\lambda_{3}^{2}\right)\right)^{2}}{(2+\theta)^{2}\left(\eta_{3} \lambda_{2}^{2}+\eta_{2}\left(-4 \eta_{3}\left(2-3 \theta+\theta^{2}\right)+\lambda_{3}^{2}\right)\right)^{2}}$ \\
\hline
\end{tabular}



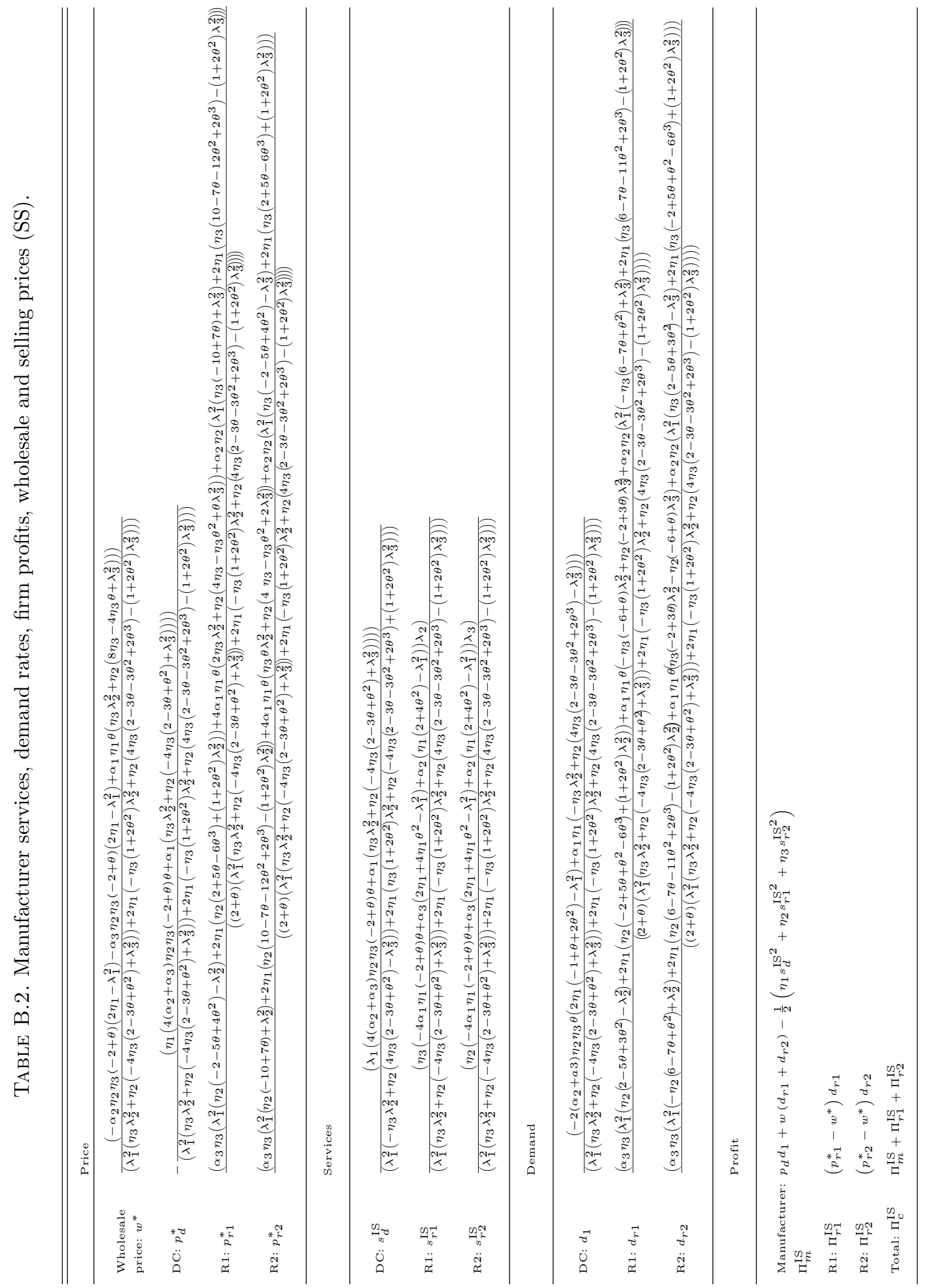


\section{Appendix C. Solution procedure under SA}

We obtained the optimal values of the decision variables of the total profit function, $\Pi_{T}$ in Table C.1 as follows:

(1) We solve the first-order condition of the profit function $\Pi_{T}$ with respect to its decision variables $p_{r 1}, p_{r 2}, s_{r 1}$ and $s_{r 2}$.

(2) If the Hessian matrix of $\Pi_{T}$ for the decision variables is negative definite at the above-mentioned values, then the values are optimal. We listed the values of the decision variables and the total profit in Table C.1.

TABLE C.1. Services, demand rates, firm profits and selling prices without any direct channel (SA).

\begin{tabular}{ll}
\hline \hline & Price \\
\hline $\mathrm{R} 1: p_{r 1}$ & $\frac{\eta_{2}\left(-2 \beta_{2} \eta_{3} \theta+\beta_{1}\left(-2 \eta_{3}+\lambda_{3}^{2}\right)\right)}{\lambda_{2}^{2}\left(2 \eta_{3}-\lambda_{3}^{2}\right)+2 \eta_{2}\left(2 \eta_{3}\left(-1+\theta^{2}\right)+\lambda_{3}^{2}\right)}$ \\
$\mathrm{R} 2: p_{r 2}$ & $\frac{\eta_{3}\left(-2 \beta_{1} \eta_{2} \theta+\beta_{2}\left(-2 \eta_{2}+\lambda_{2}^{2}\right)\right)}{\lambda_{2}^{2}\left(2 \eta_{3}-\lambda_{3}^{2}\right)+2 \eta_{2}\left(2 \eta_{3}\left(-1+\theta^{2}\right)+\lambda_{3}^{2}\right)}$ \\
\hline $\mathrm{R} 1: s_{r 1}^{\mathrm{NC}}$ & $\frac{\lambda_{2}\left(-2 \beta_{2} \eta_{3} \theta+\beta_{1}\left(-2 \eta_{3}+\lambda_{3}^{2}\right)\right)}{\lambda_{2}^{2}\left(2 \eta_{3}-\lambda_{3}^{2}\right)+2 \eta_{2}\left(2 \eta_{3}\left(-1+\theta^{2}\right)+\lambda_{3}^{2}\right)}$ \\
$\mathrm{R} 2: s_{r 2}^{\mathrm{NC}}$ & $\frac{\left(-2 \beta_{1} \eta_{2} \theta+\beta_{2}\left(-2 \eta_{2}+\lambda_{2}^{2}\right)\right) \lambda_{3}}{\lambda_{2}^{2}\left(2 \eta_{3}-\lambda_{3}^{2}\right)+2 \eta_{2}\left(2 \eta_{3}\left(-1+\theta^{2}\right)+\lambda_{3}^{2}\right)}$ \\
\hline $\mathrm{Remand}$ & Demand $d_{r 1}$ \\
$\mathrm{R} 2: d_{r 2}$ & $\frac{-\beta_{2} \eta_{3} \theta \lambda_{2}^{2}+\beta_{1} \eta_{2}\left(2 \eta_{3}\left(-1+\theta^{2}\right)+\lambda_{3}^{2}\right)}{\lambda_{2}^{2}\left(2 \eta_{3}-\lambda_{3}^{2}\right)+2 \eta_{2}\left(2 \eta_{3}\left(-1+\theta^{2}\right)+\lambda_{3}^{2}\right)}$ \\
\hline & $\frac{\beta_{2} \eta_{3}\left(2 \eta_{2}\left(-1+\theta^{2}\right)+\lambda_{2}^{2}\right)-\beta_{1} \eta_{2} \theta \lambda_{3}^{2}}{\lambda_{2}^{2}\left(2 \eta_{3}-\lambda_{3}^{2}\right)+2 \eta_{2}\left(2 \eta_{3}\left(-1+\theta^{2}\right)+\lambda_{3}^{2}\right)}$ \\
\hline Manufacturer: $\Pi_{c}^{\mathrm{NC}}$ & $\frac{-4 \beta_{1} \beta_{2} \eta_{2} \eta_{3} \theta+\beta_{2}^{2} \eta_{3}\left(-2 \eta_{2}+\lambda_{2}^{2}\right)+\beta_{1}^{2} \eta_{2}\left(-2 \eta_{3}+\lambda_{3}^{2}\right)}{2 \lambda_{2}^{2}\left(2 \eta_{3}-\lambda_{3}^{2}\right)+4 \eta_{2}\left(2 \eta_{3}\left(-1+\theta^{2}\right)+\lambda_{3}^{2}\right)}$ \\
\hline
\end{tabular}

In similar procedure, we can obtain the optimal values of the decision variables when manufacturer added a direct channel and listed in Table C.2. 
TABle C.2. Manufacturer services, demand rates, firm total profits, retail prices and direct channel price (SA).

\begin{tabular}{|c|c|}
\hline & Price \\
\hline $\mathrm{DC}: p_{d}^{*}$ & $\frac{\left(\eta_{1}\left(2 \theta\left(\alpha_{3} \eta_{3}\left(-2 \eta_{2}(1+\theta)+\lambda_{2}^{2}\right)+\alpha_{2} \eta_{2}\left(-2 \eta_{3}(1+\theta)+\lambda_{3}^{2}\right)\right)+\alpha_{1}\left(\lambda_{2}^{2}\left(2 \eta_{3}-\lambda_{3}^{2}\right)+2 \eta_{2}\left(2 \eta_{3}\left(-1+\theta^{2}\right)+\lambda_{3}^{2}\right)\right)\right)\right)}{\left(\lambda_{1}^{2}\left(\lambda_{2}^{2}\left(-2 \eta_{3}+\lambda_{3}^{2}\right)-2 \eta_{2}\left(2 \eta_{3}\left(-1+\theta^{2}\right)+\lambda_{3}^{2}\right)\right)+2 \eta_{1}\left(-\lambda_{2}^{2}\left(2 \eta_{3}\left(-1+\theta^{2}\right)+\lambda_{3}^{2}\right)+2 \eta_{2}(1+\theta)\left(2 \eta_{3}\left(-1+\theta+2 \theta^{2}\right)-(-1+\theta) \lambda_{3}^{2}\right)\right)\right)}$ \\
\hline $\mathrm{R} 1: p_{r 1}^{*}$ & $\frac{\left(\eta_{2}\left(2 \theta\left(\alpha_{3} \eta_{3}\left(-2 \eta_{1}(1+\theta)+\lambda_{1}^{2}\right)+\alpha_{1} \eta_{1}\left(-2 \eta_{3}(1+\theta)+\lambda_{3}^{2}\right)\right)+\alpha_{2}\left(\lambda_{1}^{2}\left(2 \eta_{3}-\lambda_{3}^{2}\right)+2 \eta_{1}\left(2 \eta_{3}\left(-1+\theta^{2}\right)+\lambda_{3}^{2}\right)\right)\right)\right)}{\left(\lambda_{1}^{2}\left(\lambda_{2}^{2}\left(-2 \eta_{3}+\lambda_{3}^{2}\right)-2 \eta_{2}\left(2 \eta_{3}\left(-1+\theta^{2}\right)+\lambda_{3}^{2}\right)\right)+2 \eta_{1}\left(-\lambda_{2}^{2}\left(2 \eta_{3}\left(-1+\theta^{2}\right)+\lambda_{3}^{2}\right)+2 \eta_{2}(1+\theta)\left(2 \eta_{3}\left(-1+\theta+2 \theta^{2}\right)-(-1+\theta) \lambda_{3}^{2}\right)\right)\right)}$ \\
\hline \multirow[t]{2}{*}{$\mathrm{R} 2: p_{r 2}^{*}$} & $\frac{\left(\eta_{3}\left(2 \theta\left(\alpha_{2} \eta_{2}\left(-2 \eta_{1}(1+\theta)+\lambda_{1}^{2}\right)+\alpha_{1} \eta_{1}\left(-2 \eta_{2}(1+\theta)+\lambda_{2}^{2}\right)\right)+\alpha_{3}\left(\lambda_{1}^{2}\left(2 \eta_{2}-\lambda_{2}^{2}\right)+2 \eta_{1}\left(2 \eta_{2}\left(-1+\theta^{2}\right)+\lambda_{2}^{2}\right)\right)\right)\right)}{\left(\lambda_{1}^{2}\left(\lambda_{2}^{2}\left(-2 \eta_{3}+\lambda_{3}^{2}\right)-2 \eta_{2}\left(2 \eta_{3}\left(-1+\theta^{2}\right)+\lambda_{3}^{2}\right)\right)+2 \eta_{1}\left(-\lambda_{2}^{2}\left(2 \eta_{3}\left(-1+\theta^{2}\right)+\lambda_{3}^{2}\right)+2 \eta_{2}(1+\theta)\left(2 \eta_{3}\left(-1+\theta+2 \theta^{2}\right)-(-1+\theta) \lambda_{3}^{2}\right)\right)\right)}$ \\
\hline & Services \\
\hline $\mathrm{DC}: s_{d}^{\mathrm{IC}}$ & $-\frac{\left(\lambda_{1}\left(2 \theta\left(\alpha_{3} \eta_{3}\left(-2 \eta_{2}(1+\theta)+\lambda_{2}^{2}\right)+\alpha_{2} \eta_{2}\left(-2 \eta_{3}(1+\theta)+\lambda_{3}^{2}\right)\right)+\alpha_{1}\left(\lambda_{2}^{2}\left(2 \eta_{3}-\lambda_{3}^{2}\right)+2 \eta_{2}\left(2 \eta_{3}\left(-1+\theta^{2}\right)+\lambda_{3}^{2}\right)\right)\right)\right)}{\left(\lambda_{1}^{2}\left(\lambda_{2}^{2}\left(2 \eta_{3}-\lambda_{3}^{2}\right)+2 \eta_{2}\left(2 \eta_{3}\left(-1+\theta^{2}\right)+\lambda_{3}^{2}\right)\right)+\eta_{1}\left(2 \lambda_{2}^{2}\left(2 \eta_{3}\left(-1+\theta^{2}\right)+\lambda_{3}^{2}\right)-4 \eta_{2}(1+\theta)\left(2 \eta_{3}\left(-1+\theta+2 \theta^{2}\right)-(-1+\theta) \lambda_{3}^{2}\right)\right)\right)}$ \\
\hline $\mathrm{R} 1: s_{r 1}^{\mathrm{IC}}$ & $-\frac{\left(\lambda_{2}\left(2 \theta\left(\alpha_{3} \eta_{3}\left(-2 \eta_{1}(1+\theta)+\lambda_{1}^{2}\right)+\alpha_{1} \eta_{1}\left(-2 \eta_{3}(1+\theta)+\lambda_{3}^{2}\right)\right)+\alpha_{2}\left(\lambda_{1}^{2}\left(2 \eta_{3}-\lambda_{3}^{2}\right)+2 \eta_{1}\left(2 \eta_{3}\left(-1+\theta^{2}\right)+\lambda_{3}^{2}\right)\right)\right)\right)}{\left(\lambda_{1}^{2}\left(\lambda_{2}^{2}\left(2 \eta_{3}-\lambda_{3}^{2}\right)+2 \eta_{2}\left(2 \eta_{3}\left(-1+\theta^{2}\right)+\lambda_{3}^{2}\right)\right)+\eta_{1}\left(2 \lambda_{2}^{2}\left(2 \eta_{3}\left(-1+\theta^{2}\right)+\lambda_{3}^{2}\right)-4 \eta_{2}(1+\theta)\left(2 \eta_{3}\left(-1+\theta+2 \theta^{2}\right)-(-1+\theta) \lambda_{3}^{2}\right)\right)\right)}$ \\
\hline \multirow[t]{2}{*}{$\mathrm{R} 2: s_{r 2}^{\mathrm{IC}}$} & $\frac{\left(\left(2 \theta\left(\alpha_{2} \eta_{2}\left(-2 \eta_{1}(1+\theta)+\lambda_{1}^{2}\right)+\alpha_{1} \eta_{1}\left(-2 \eta_{2}(1+\theta)+\lambda_{2}^{2}\right)\right)+\alpha_{3}\left(\lambda_{1}^{2}\left(2 \eta_{2}-\lambda_{2}^{2}\right)+2 \eta_{1}\left(2 \eta_{2}\left(-1+\theta^{2}\right)+\lambda_{2}^{2}\right)\right)\right) \lambda_{3}\right)}{\left(\lambda_{1}^{2}\left(\lambda_{2}^{2}\left(-2 \eta_{3}+\lambda_{3}^{2}\right)-2 \eta_{2}\left(2 \eta_{3}\left(-1+\theta^{2}\right)+\lambda_{3}^{2}\right)\right)+2 \eta_{1}\left(-\lambda_{2}^{2}\left(2 \eta_{3}\left(-1+\theta^{2}\right)+\lambda_{3}^{2}\right)+2 \eta_{2}(1+\theta)\left(2 \eta_{3}\left(-1+\theta+2 \theta^{2}\right)-(-1+\theta) \lambda_{3}^{2}\right)\right)\right)}$ \\
\hline & Demand \\
\hline DC: $d_{1}$ & $\frac{\theta \lambda_{1}^{2}\left(\alpha_{3} \eta_{3}\left(\lambda_{2}^{2}-2 \eta_{2}(1+\theta)\right)+\alpha_{2} \eta_{2}\left(\lambda_{3}^{2}-2 \eta_{3}(1+\theta)\right)\right)+\alpha_{1} \eta_{1}\left(+2 \eta_{2}(1+\theta)\left(2 \eta_{3}\left(\theta+2 \theta^{2}-1\right)+(1-\theta) \lambda_{3}^{2}\right)-\lambda_{2}^{2}\left(2 \eta_{3}\left(\theta^{2}-1\right)+\lambda_{3}^{2}\right)\right)}{\lambda_{1}^{2}\left(\lambda_{2}^{2}\left(-2 \eta_{3}+\lambda_{3}^{2}\right)-2 \eta_{2}\left(2 \eta_{3}\left(-1+\theta^{2}\right)+\lambda_{3}^{2}\right)\right)+2 \eta_{1}\left(-\lambda_{2}^{2}\left(2 \eta_{3}\left(-1+\theta^{2}\right)+\lambda_{3}^{2}\right)+2 \eta_{2}(1+\theta)\left(2 \eta_{3}\left(-1+\theta+2 \theta^{2}\right)-(-1+\theta) \lambda_{3}^{2}\right)\right)}$ \\
\hline $\mathrm{R} 1: d_{r 1}$ & $\frac{\theta \lambda_{2}^{2}\left(\alpha_{3} \eta_{3}\left(\lambda_{1}^{2}-2 \eta_{1}(1+\theta)\right)+\alpha_{1} \eta_{1}\left(\lambda_{3}^{2}-2 \eta_{3}(1+\theta)\right)\right)+\alpha_{2} \eta_{2}\left(-\lambda_{1}^{2}\left(2 \eta_{3}\left(-1+\theta^{2}\right)+\lambda_{3}^{2}\right)+2 \eta_{1}(1+\theta)\left(2 \eta_{3}\left(\theta+2 \theta^{2}-1\right)+(1-\theta) \lambda_{3}^{2}\right)\right)}{\left(\lambda_{1}^{2}\left(\lambda_{2}^{2}\left(-2 \eta_{3}+\lambda_{3}^{2}\right)-2 \eta_{2}\left(2 \eta_{3}\left(-1+\theta^{2}\right)+\lambda_{3}^{2}\right)\right)+2 \eta_{1}\left(-\lambda_{2}^{2}\left(2 \eta_{3}\left(-1+\theta^{2}\right)+\lambda_{3}^{2}\right)+2 \eta_{2}(1+\theta)\left(2 \eta_{3}\left(-1+\theta+2 \theta^{2}\right)-(-1+\theta) \lambda_{3}^{2}\right)\right)\right)}$ \\
\hline \multirow[t]{2}{*}{$\mathrm{R} 2: d_{r 2}$} & $\frac{\left(\alpha_{3} \eta_{3}\left(\lambda_{1}^{2}\left(2 \eta_{2}\left(1-\theta^{2}\right)-\lambda_{2}^{2}\right)+2 \eta_{1}(1+\theta)\left(2 \eta_{2}\left(-1+\theta+2 \theta^{2}\right)+(1-\theta) \lambda_{2}^{2}\right)\right)+\theta\left(\alpha_{2} \eta_{2}\left(\lambda_{1}^{2}-2 \eta_{1}(1+\theta)\right)+\alpha_{1} \eta_{1}\left(\lambda_{2}^{2}-2 \eta_{2}(1+\theta)\right)\right) \lambda_{3}^{2}\right)}{\left(\lambda_{1}^{2}\left(\lambda_{2}^{2}\left(-2 \eta_{3}+\lambda_{3}^{2}\right)-2 \eta_{2}\left(2 \eta_{3}\left(-1+\theta^{2}\right)+\lambda_{3}^{2}\right)\right)+2 \eta_{1}\left(-\lambda_{2}^{2}\left(2 \eta_{3}\left(-1+\theta^{2}\right)+\lambda_{3}^{2}\right)+2 \eta_{2}(1+\theta)\left(2 \eta_{3}\left(-1+\theta+2 \theta^{2}\right)-(-1+\theta) \lambda_{3}^{2}\right)\right)\right)}$ \\
\hline & Profit \\
\hline Total: $\Pi_{c}^{\mathrm{IS}}$ & $p_{r 1}^{*} d_{r 1}+p_{r 2}^{*} d_{r 2}+p_{d}^{*} d_{1}-\frac{1}{2}\left(\eta_{1} s_{d}^{\mathrm{IC}^{2}}+\eta_{2} s_{r 1}^{\mathrm{IC}^{2}}+\eta_{3} s_{r 2}^{\mathrm{IC}^{2}}\right)$ \\
\hline
\end{tabular}

\section{Appendix D. Solution PROCEDURE UNDER NIS FORM I}

At first we put the values of $s_{r 1}$ and $s_{r 2}$ (taken from Tab. B.1) in the equations 3.1-3.3 and let the revised profit functions are $\Pi_{r 1}^{\prime}, \Pi_{r 2}^{\prime}$ and $\Pi_{m}^{\prime}$ respectively. Then we solve the first order condition of $\Pi_{r 1}^{\prime}$ and $\Pi_{r 2}^{\prime}$ with respect to $p_{r 1}$ and $p_{r 2}$ respectively. Then putting these values to $\Pi_{m}^{\prime}$, we solve the first order condition of this profit function with respect to wholesale price $(w)$ and direct channel price $\left(p_{d}\right)$, namely, $w^{*}$ and $p_{d}^{*}$ respectively. If the Hessian matrix of $\Pi_{m}^{\prime}$ is negative definite at the values $w^{*}$ and $p_{d}^{*}$, then the profit function is maximum and consequently $w^{*}$ and $p_{d}^{*}$ are the optimal values of $w$ and $p_{d}$ respectively. Using these values, we can obtain the optimal values of $p_{r 1}$ and $p_{r 2}$ and also the maximum profits of the retailers. We tabulated these results in Table D.1.

Similarly, we can maximize the profits and also determines the optimal values of the decision variables under NIS form II. We listed the optimal decision variables and the profits in the Table D.2. 


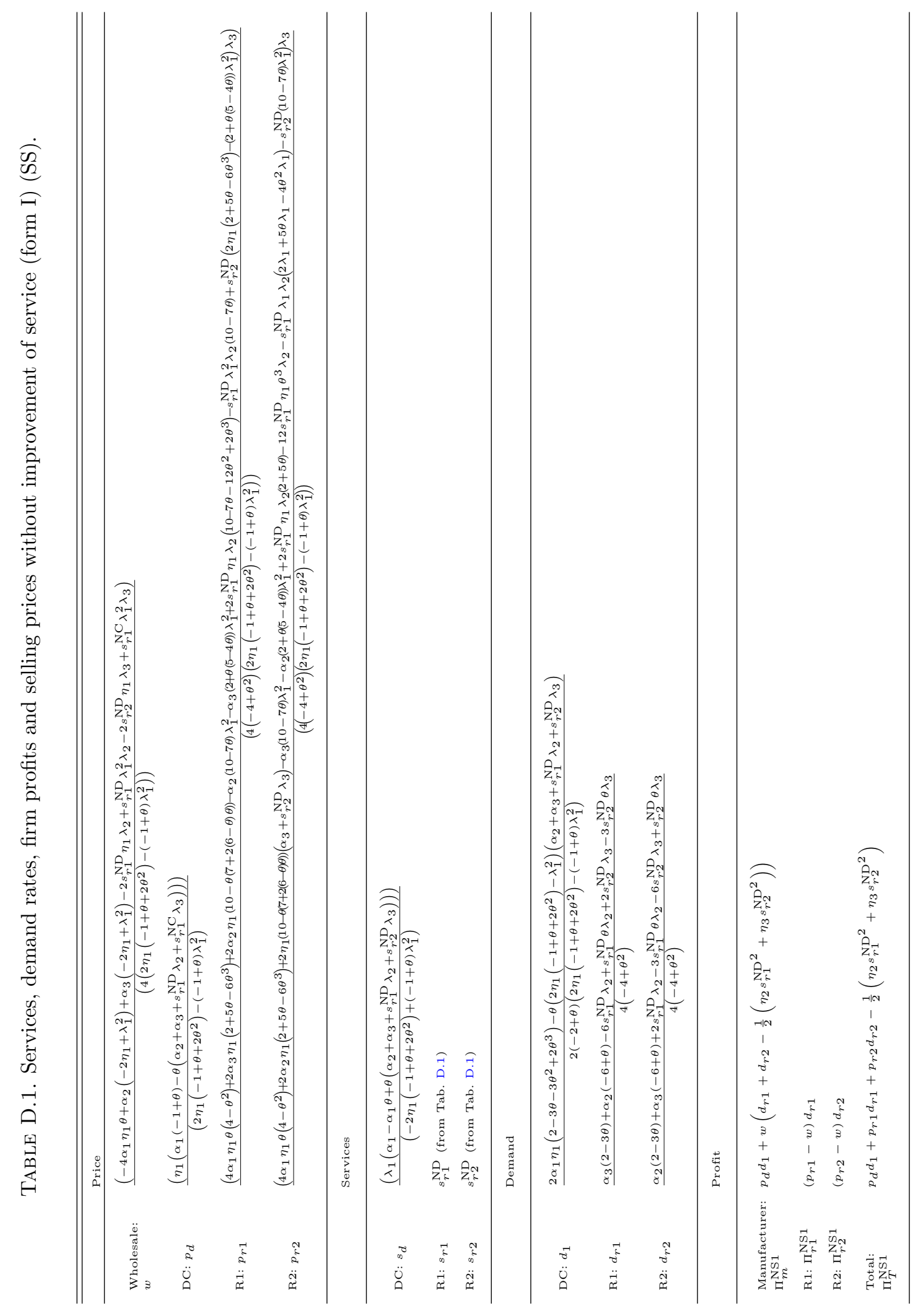




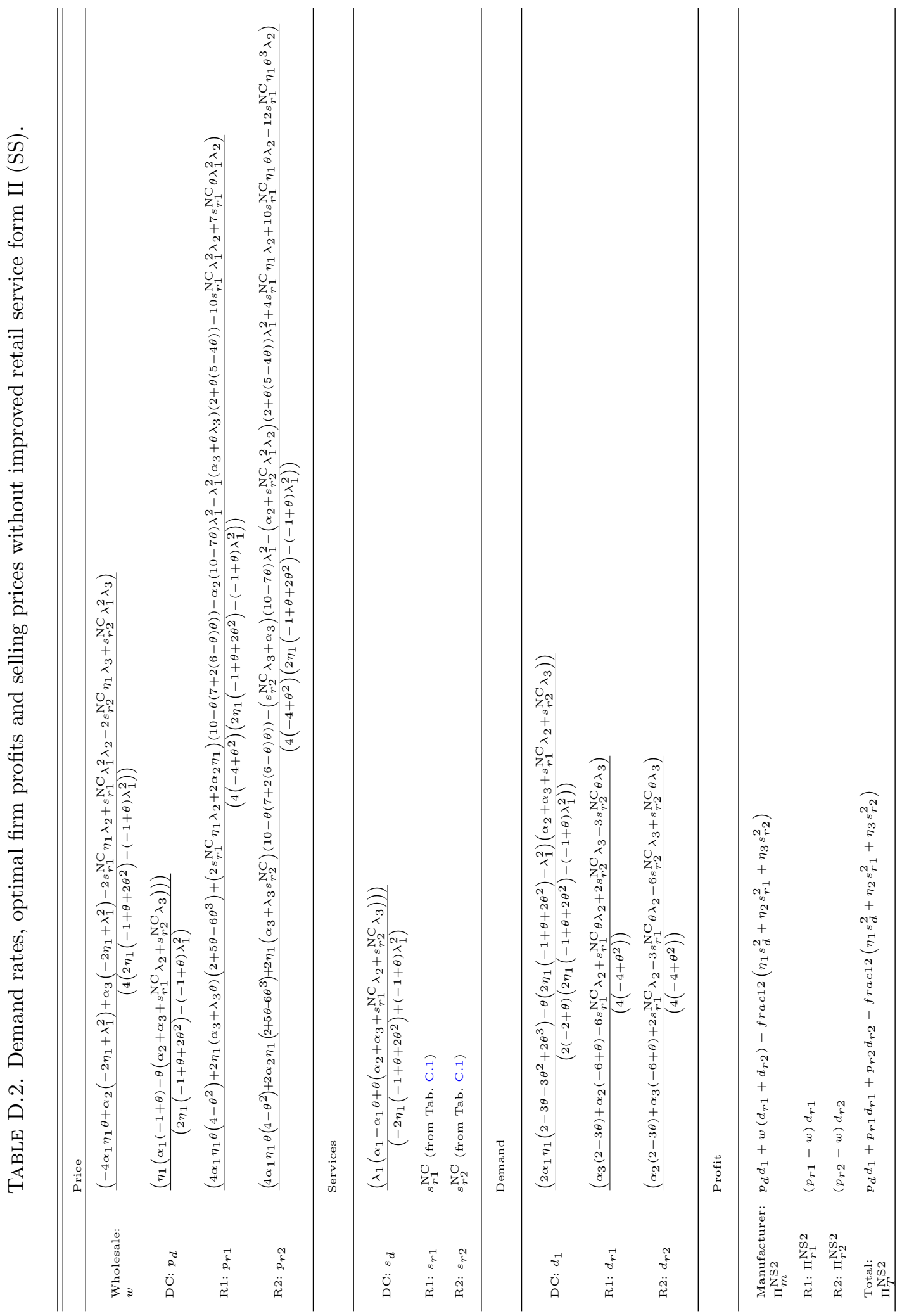




\section{REFERENCES}

[1] O. Benedettini, M. Swink and A. Neely, Examining the influence of service additions on manufacturing firms' bankruptcy likelihood. Ind. Mark. Manage. 60 (2017) 112-125.

[2] R. Bhattacharya, A. Kaur and R.K. Amit, Price optimization of multi-stage remanufacturing in a closed loop supply chain. J. Clean. Prod. 186 (2018) 943-962.

[3] I. Biswas, A. Raj and S.K. Srivastava, Supply chain channel coordination with triple bottom line approach. Transp. Res. Part E: Logist. Transp. Rev. 115 (2018) 213-226.

[4] S. Bogomolova, M. Szabo and A. Kennedy, Retailers' and manufacturers' price-promotion decisions: intuitive or evidence-based? J. Bus. Res. 76 (2017) 189-200.

[5] J. Burton, V.M. Story, C. Raddats and J. Zolkiewski, Overcoming the challenges that hinder new service development by manufacturers with diverse services strategies. Int. J. Prod. Econ. 192 (2017) 29-39.

[6] G. Büyüközkan and F. Göçer, Digital supply chain: literature review and a proposed framework for future research. Comput. Ind. 97 (2018) 157-177.

[7] G. Cainelli and F. Göçer, Environmental innovations in services: manufacturingservices integration and policy transmissions. Res. Policy 42 (2013) 1595-1604.

[8] K.-Y. Chen, M. Kaya and Ö. Özer, Dual sales channel management with service competition. Manuf. Serv. Oper. Manage. 10 (2008) 654-675.

[9] W.-Y.K. Chiang, D. Chhajed and J.D. Hess, Direct marketing, indirect profits: a strategic analysis of dual-channel supply-chain design. Manage. Sci. 49 (2003) 1-20.

[10] B. Dan, Q. He, K. Zheng and R. Liu, Ordering and pricing model of retailers preventive transshipment dominated by manufacturer with conditional return. Comput. Ind. Eng. 100 (2016) 24-33.

[11] L. Ding, H.K.S. Lam, T.C.E. Cheng and H. Zhou, A review of short-term event studies in operations and supply chain management. Int. J. Prod. Econ. 200 (2018) 329-342.

[12] A. Dumrongsiri, M. Fan, A. Jain and K. Moinzadeh, A supply chain model with direct and retail channels. Eur. J. Oper. Res. 187 (2008) 691-718.

[13] D. Fan, Q. Xu, T. Fan and F. Cheng, Inventory optimization model considering consumer shift and inventory transshipment in dual-channel supply chains. RAIRO:OR $\mathbf{5 3}$ (2019) 59-79.

[14] J.H. Hamilton and S.M. Slutsky, Endogenous timing in duopoly games: Stackelberg or Cournot equilibria. Games Econ. Behav. 2 (1990) 29-46.

[15] M. Hoseininia, M.M.S. Esfahani, F. Didehvar and A. Haghi, Inventory competition in a multi channel distribution system: the Nash and Stackelberg game. Sci. Iran. 20 (2013) 846-854.

[16] W. Huang and J.M. Swaminathan, Introduction of a second channel: implications for pricing and profits. Eur. J. Oper. Res. 194 (2009) 258-279.

[17] H. Jafari, S.R. Hejazi and M. Rasti-Barzoki, Pricing decisions in dual-channel supply chain with one manufacturer and multiple retailers: a game-theoretic approach. RAIRO:OR 51 (2017) 1269-1287.

[18] J.J. Kacen, J.D. Hess and W.-Y.K. Chiang, Bricks or clicks? Consumer attitudes toward traditional stores and online stores. Global Econ. Manage. Rev. 18 (2013) 12-21.

[19] S. Kolay, Manufacturer-provided services vs. retailer-provided services: effect on product quality, channel profits and consumer welfare. Int. J. Res. Mark. 32 (2015) 124-154.

[20] N. Kumar and R. Ruan, On manufacturers complementing the traditional retail channel with a direct online channel. Quant. Mark. Econ. 4 (2006) 289-323.

[21] G. Li, L. Li and J. Sun, Pricing and service effort strategy in a dual-channel supply chain with showrooming effect. Transp. Res. Part E: Logist. Transp. Rev. 126 (2019) 32-48.

[22] Z. Liu, J. Chen and C. Diallo, Optimal production and pricing strategies for a remanufacturing firm. Int. J. Prod. Econ. 204 (2018) 290-315.

[23] J.-C. Lu, Y.-C. Tsao and C. Charoensiriwath, Competition under manufacturer service and retail price. Econ. Model. 28 (2011) 1256-1264.

[24] A.J. Magrath and K.G. Hardy, Manufactuer services for distributor. Ind. Mark. Manage. 21 (1992) 119-124.

[25] K. Matsui, When and what wholesale and retail prices should be set in multi-channel supply chains? Eur. J. Oper. Res. 267 (2018) 540-554.

[26] K. Okuda, N. Nishino and K. Ueda, Modelling and theoretical analysis of membership-type services in manufacturing industries. SciVerse ScienceDirect, Proc. CIRP 3 (2012) 495-500.

[27] B. Pal, S.S. Sana and K. Chaudhuri, Two-echelon manufacturerretailer supply chain strategies with price, quality, and promotional effort sensitive demand. Int. Trans. Oper. Res. 22 (2015) 1071-1095.

[28] V. Rajagopal, P.S. Venkatesan and M. Goh, Decision-making models for supply chain risk mitigation: a review. Comput. Ind. Eng. 113 (2017) 646-682.

[29] A. Rangaswamy and G.H.V. Bruggen, Opportunities and challenges in multichannel marketing: an introduction to the special issue. J. Interact. Mark. 19 (2005) 5-11.

[30] M. Ren, L. Ren and H. Jain, Manufacturing service composition model based on synergy effect: a social network analysis approach. Appl. Soft Comput. 70 (2018) 288-300. 
[31] B. Rosenbloom, Multi-channel strategy in business-to-business markets: prospects and problems. Ind. Mark. Manage. 36 (2007) $4-9$.

[32] J.R. Silva and S.Y. Nof, Manufacturing service: from e-work and service-oriented approach towards a product-service architecture. IFAC-PapersOnLine 48 (2015) 1628-1633.

[33] M. Toloo, Selecting and full ranking suppliers with imprecise data: a new DEA method. Int. J. Adv. Manuf. Technol. 74 (2014) 1141-1148.

[34] M. Toloo and M. Barat, On considering dual-role factor in supplier selection problem. Math. Methods Oper. Res. 82 (2015) $107-122$.

[35] J. Vries, J. Schepers, A. Weele and W. Valk, When do they care to share? How manufacturers make contracted service partners share knowledge. Ind. Mark. Manage. 43 (2014) 1225-1235.

[36] W. Wang, G. Li and T.C.E. Cheng, Channel selection in a supply chain with a multi-channel retailer: the role of channel operating costs. Int. J. Prod. Econ. 173 (2016) 54-65.

[37] L. Wang, H. Song and Y. Wang, Pricing and service decisions of complementary products in a dual-channel supply chain. Comput. Ind. Eng. 105 (2017) 223-233.

[38] A. Wolk and C. Ebling, Multi-channel price differentiation: an empirical investigation of existence and causes. Int. J. Res. Mark. 27 (2010) 142-150.

[39] X. Xue, S. Wang and B. Lu, Manufacturing service composition method based on networked collaboration mode. J. Netw. Comput. App. 59 (2016) 28-38.

[40] R. Yan, Managing channel coordination in a multi-channel manufacturerretailer supply chain. Ind. Mark. Manage. 40 (2011) 636-642.

[41] R. Yan and Z. Pei, Retail service and firm profit in a dual-channel market. J. Retail. Consum. Serv. 16 (2009) $306-314$.

[42] R. Yan and Z. Pei, Information asymmetry, pricing strategy and firm's performance in the retailer-multi-channel manufacturer supply chain. J. Bus. Res. 64 (2011) 377-384.

[43] H. Yang, L. Chu and H. Wan, Advertising and pricing policies in a two-echelon supply chain with a capital-constrained retailer. RAIRO:OR 53 (2019) 1331-1342.

[44] D.-Q. Yao and J.J. Liu, Competitive pricing of mixed retail and e-tail distribution channels. Omega 33 (2005) $235-247$.

[45] J. Zhao and L. Wang, Pricing and retail service decisions in fuzzy uncertainty environments. Appl. Math. Comput. 250 (2015) $580-592$.

[46] J. Zhao, W. Liu and J. Wei, Competition under manufacturer service and price in fuzzy environments. Knowl. Based Syst. 50 (2013) 121-133.

[47] Y.-W. Zhou, J. Guo and W. Zhou, Pricing/service strategies for a dual-channel supply chain with free riding and service-cost sharing. Int. J. Prod. Econ. 196 (2018) 198-210.

[48] R. Zhu and M. Xue, Two-period pricing strategies in a two-echlon supply chain with conspicuous consumption. RAIRO:OR 53 (2019) 667-685. 